\title{
Knowledge Based Integrated Multidisciplinary Aircraft Conceptual Design
}

\section{Venkata Raghu Chaitanya Munjulury (Raghu Chaitanya.M.V)}

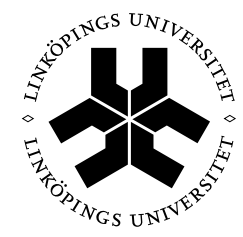

\section{Linköping University}

INSTITUTE OF TECHNOLOGY

\author{
Division of Fluid and Mechatronic Systems \\ Department of Management and Engineering \\ Linköping University, SE-581 83 Linköping, Sweden
}




\section{Cover:}

"Johnson's Theorem: If three congruent circles all intersect in a single point, then the other three points of intersection will lie on another circle of the same radius. This simple little theorem was discovered by Roger Johnson(1890-1954) in 1916. The anti-complementary circle is tangent to the three Johnson circles and the radius is twice that of the Johnson circles."

Copyright (C) Venkata Raghu Chaitanya Munjulury (Raghu Chaitanya.M.V), 2014

Knowledge Based Integrated Multidisciplinary Aircraft Conceptual Design

ISBN 978-91-7519-328-1

ISSN 0280-7971

\section{Distributed by:}

Division of Fluid and Mechatronic Systems

Department of Management and Engineering

Linköping University

SE-581 83 Linköping, Sweden

Printed in Sweden by LiU-Tryck, Linköping 2014. 
To Krishnaveni 
Arise! Awake! and Stop not until the Goal is reached.

- Swami Vivekananda 


\section{Abstract}

With the ever growing complexity of aircrafts, new tools and eventually methods to use these tools are needed in aircraft conceptual design. To reduce the development cost, an enhancement in the conceptual design is needed.

This thesis presents a knowledge-based aircraft geometry design tool RAPID and the methodology applied in realizing the design. The parameters used to create a geometry need to be exchange between different tools. This is achieved by using a centralized database or onedata concept. One-database will enable creating a less number of cross connections between different tools to exchange data with one another. Different types of aircraft configurations can be obtained with less effort. As RAPID is developed based on relational design, any changes made to the geometric model will update automatically. The geometry model is carefully defined to carry over to the preliminary design.

The validation of RAPID is done by implementing it in different aircraft design courses at Linköping University. In the aircraft project course, RAPID was effectively used and new features were added to the obtained desired design. Knowledge-base is used to realize the design performance for the geometry with an integrated database approach for a multidisciplinary aircraft conceptual design.

Keywords: Knowledge-base, Aircraft, Conceptual Design, CAD, XML Database, Multidisciplinary, Optimization 


\section{Acknowledgements}

The work presented has been conducted at the Division of Fluid and Mechatronic Systems (FluMeS), Linköping University, Sweden. There are several people I would like to thank. First of all, Prof. Petter Krus, for his valuable support, encouragement and for offering me an opportunity to be a part of research project and this division. I would like to thank Dr. Tomas Melin, Dr. Christopher Jouannet, Dr. Kristian Amadori and Dr. Mehdi Tarkian for their valuable discussions during the work conducted for this thesis. Dr. David Lundström, the project course team leader and test pilot for his great efforts in the Aircraft Project course for the year 2013.

My special thanks to Patrick Berry and Ingo Staack for all the knowledge shared, ideas, motivation and debates that made this work possible. I would like to show appreciation to all the co-authors of all the papers in the thesis. My thanks to Katharina Baer for sharing thoughts and conversations during the walks to grab a cup of coffee. I thank Peter

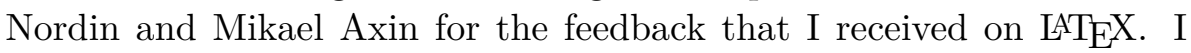
would like to thank all the colleagues of the Division of Fluid and Mechatronics Systems and Division of Machine Design for making this a better place to work.

Funding of this work was provided by NFFP, the Swedish National Aviation Engineering Program. I would like to thank the NFFP for the support and the students of Aircraft Conceptual Design and Aircraft Project courses of the Linköping University for their excellent work during the courses.

I would like to thank my friends that have been with me through thick and thin. Last, but not least, my parents for their support and understanding; my brothers for their love and affection. A exceptional credit to my wife, Krishnaveni, for supporting and motivating me at all times. 


\section{Abbreviations}

\begin{tabular}{ll}
\hline$A D S$ & Aircraft Design Software \\
$A R$ & Aspect Ratio \\
$B e X$ & Berry Excel \\
$C A D$ & Computer Aided Design \\
$C A T I A$ & Computer Aided Three-dimensional Interactive \\
& Application \\
$C D T$ & Conceptual Design Tool \\
$C E A S I O M$ & Computerized Environment for Aircraft Synthesis \\
& and Integrated Optimisation Methods \\
$C F D$ & Computational Fluid Dynamics \\
$D O M$ & Document Object Model \\
$E K L$ & Engineering Knowledge Language \\
$F A R$ & Federal Acquisition Regulation \\
$K B S$ & Knowledge Based System \\
$K B E$ & Knowledge Based Engineering \\
$K P$ & Knowledge Pattern \\
$P A D L a b$ & Preliminary Aircraft Design Lab \\
$P C$ & Power Copy \\
$R A P I D$ & Robust Aircraft Parametric Interactive Design \\
$R A G E$ & Rapid Aerospace Geometry Engine \\
$R D S$ & Aircraft Design Software package \\
$S F C$ & Specific Fuel Consumption \\
$T R$ & Taper Ratio \\
$U D F$ & User Defined Feature \\
$V B$ & Visual Basic \\
$V B A$ & Visual Basic for Applications \\
$V S P$ & Vehicle Sketch Pad \\
$X M L$ & Extensible Markup Language \\
$X L S T$ & Extensible Stylesheet Language \\
\hline &
\end{tabular}




\section{Nomenclature}

The terminology used in this thesis are as shown in the table.

\begin{tabular}{ll}
\hline Quantity & Description \\
\hline$A_{R}$ & Aspect ratio \\
$C_{S}$ & Fuselage cross-section \\
$C_{S}^{i}$ & $i^{\text {th }}$ cross-section \\
$C_{u}$ & Upper curve \\
$C_{l}$ & Lower curve \\
$C_{c}$ & Combine curve \\
$f_{i}(Z)$ & Piecewise polynomial functions \\
$f_{u}$ & Fuselage function \\
$H_{f}$ & Height of fuselage \\
$k$ & Kink Position \\
$L_{f}$ & Length of fuselage \\
$n_{p}$ & Number of parameters \\
$P_{i}$ & Points on a spline \\
$p_{1,2, \ldots n}$ & Control points of cross-section \\
$S$ & Reference wing area \\
$S_{p}$ & Splines \\
$w$ & Wing function \\
$w_{p}$ & Wing partitions \\
$w_{p}^{i}$ & $i^{t h}$ wing partition \\
$W_{f}$ & Width of fuselage \\
$\Gamma$ & Dihedral \\
$\theta$ & Incidence/Twist \\
$\lambda$ & Taper ratio \\
$\Lambda$ & Sweep \\
$\alpha_{p_{2,3,5,6 d}}$ & Angle measured w.r.t horizontal or vertical \\
\hline &
\end{tabular}


viii 


\section{Papers}

The following Papers [I] [II] [III] [IV] are an integral part that forms this thesis and will be referred by Roman numerals. The papers are printed in their original-form with the exception of minor errata and adjustment of text and figures in-order to maintain same consistency throughout this thesis.

[I] Raghu Chaitanya M.V., Tarkian M., and Jouannet C. "Model Based Aircraft Control System Design And Simulation". In: 27th Congress of International Council of the Aeronautical Sciences. 2010.

[II] Safavi E., Raghu Chaitanya M.V., Ölvander J., and Krus P. "Multidisciplinary Optimization of Aircraft Vehicle System for Conceptual Analysis". In: Aerospace Sciences Meetings. American Institute of Aeronautics and Astronautics, Jan. 2013. DOI: 10.2514/ 6. 2013-282.

[III] Raghu Chaitanya M.V., Berry P., and Krus P. "RAPID - Robust Aircraft Parametric Interactive Design : (A Knowledge Based Aircraft Conceptual Design Tool)". In: 4th CEAS: The International Conference of the European Aerospace Societies. 2013, pp. 255262.

[IV] Raghu Chaitanya M.V., Staack I., and Krus P. "Integrated Aircraft Conceptual Design". In: 4th CEAS: The International Conference of the European Aerospace Societies. 2013, pp. 263-269. 


\section{Papers not included}

Papers $[\mathrm{V}]$ and $[\mathrm{VI}]$ are not included in this thesis, however establish a good background for this thesis.

[V] Staack I., Raghu Chaitanya M.V., Berry P., Melin T., Amadori K., Jouannet C., Lundström D., and Krus P. "Parametric Aircraft Conceptual Design Space". In: Prceedings of the 28th International Congress of the Aeronautical Sciences. 2012.

[VI] Singh A., Raghu Chaitanya M.V., Govindarajan V.K., and Krus P. "Knowledge Based Design Methodology for Generic Aircraft Windshield and Fairing-A Conceptual Approach". In: Aerospace Sciences Meetings. American Institute of Aeronautics and Astronautics, Jan. 2013. DOI: 10.2514/6.2013-469. 


\section{Contents}

1 Introduction $\quad 1$

1.1 Background . . . . . . . . . . . . . . 1

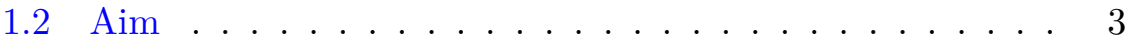

1.3 Delimitations . . . . . . . . . . . . . . . 4

1.4 Contribution ................. 4

2 Design Methodology 5

2.1 Knowledge-based Engineering and System . . . . . . . . 5

2.2 Level of fidelity . . . . . . . . . . . . . . . . . 6

2.3 Effective parametrization $\ldots \ldots \ldots \ldots \ldots$

2.3.1 Parametrization Example . . . . . . . . . . . 9

3 RAPID - Robust Aircraft Parametric Interactive Design 11

3.1 Geometry Model . . . . . . . . . . . . . . . . . . 14

3.1.1 Fuselage Geometry Description . . . . . . . . . . . 14

3.1 .2 Wing Geometry Definition . . . . . . . . . . 16

3.1 .3 Engine Design . . . . . . . . . . . . . . 17

3.2 Interior Design . . . . . . . . . . . . . . . . . 19

3.2.1 Cockpit Design . . . . . . . . . . . . . . 19

3.2 .2 Cabin Layout . . . . . . . . . . . . . . 20

4 Data Management 21

4.1 RAPID XML Export . . . . . . . . . . . . . . . 22

4.2 XML to RAPID Import . . . . . . . . . . . . . . . 24

4.3 Tango XML . . . . . . . . . . . . . . . . 25

5 Design Space $\quad 27$ 
6 Optimization Frameworks 31

6.1 Framework with adapted scripts for optimization . . . . . 31

6.2 Framework with commercial software for optimization . . 32

6.3 Framework with common database for optimization . . . 34

7 Applications of RAPID $\quad 37$

7.1 Data translation RAPID/Tango implementation . . . . 37

7.1.1 Civil Aircraft Example . . . . . . . . . . . . . 37

7.1.2 Military Aircraft Example . . . . . . . . . . . . 38

7.2 Academic Implementation . . . . . . . . . . . . . . . 38

7.2 .1 The Jet Family Project . . . . . . . . . . . . . . 39

7.2 .2 The Mid-Jet aircraft Project . . . . . . . . . . . 40

7.2 .3 Very Light Jets(VLJs) . . . . . . . . . . . . . . 41

8 Conclusion 43

9 Outlook 45

10 Review of Papers $\quad 47$

$\begin{array}{ll}\text { Bibliography } & 49\end{array}$

\section{Appended papers}

I Model Based Aircraft Control System Design And Simulation

II Multidisciplinary Optimization of Aircraft Vehicle System for Conceptual Analysis

III RAPID - Robust Aircraft Parametric Interactive Design: A Knowledge Based Aircraft Conceptual Design Tool

IV Integrated Aircraft Design Network 


\section{1 \\ Introduction}

Conceptual design is the early stage of aircraft design process where results are needed fast, both analytically and visually so that the design can be analysed and eventually improved in the initial phases. Although there is no necessity for a Computer Aided Design (CAD) model from the very beginning of the design process, it can be an added advantage to have the model to get the impression and appearance.

\subsection{Background}

AIRCRAFT DESIGN is a complex process that involves different disciplines together to obtain a holistic approach. Modern aircraft have become more expensive and the time taken to build has increased considerably [1]. Figure 1.1 shows delay in different aircraft projects. An improvement in the conceptual design is needed to decrease the overall development time and cost for an aircraft. In conceptual design the results are needed faster both analytically and visually so that the design can be modified or changed at the earlier stages.

The three main design stages of an aircraft design process are Conceptual design, Preliminary design and Detail design. After the Detail design the aircraft is verified by experimenting with a prototype testing and finally full production [2] as shown in Figure 1.2. Different designs need to be analysed and verified in the conceptual design before going with the preliminary design. The design has to be approved before continuing with the preliminary design as it incurs an increase in the cost of the project.

Conceptual design tools have a constant need for refinement and im- 


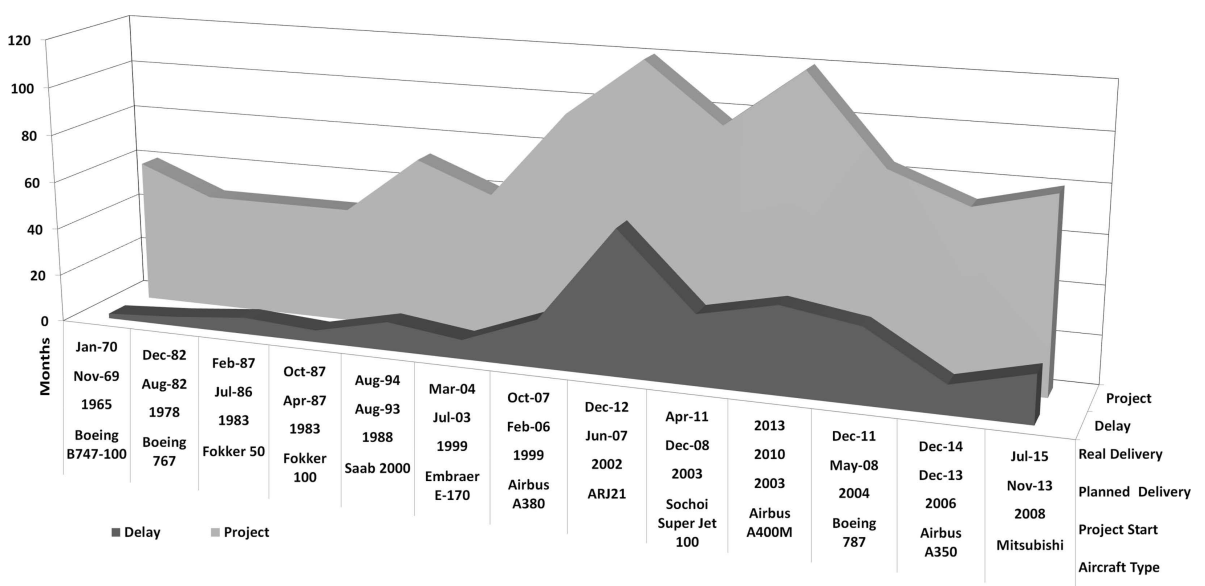

Figure 1.1 Time delay in Aircraft projects (adapted from Scminder) [1].

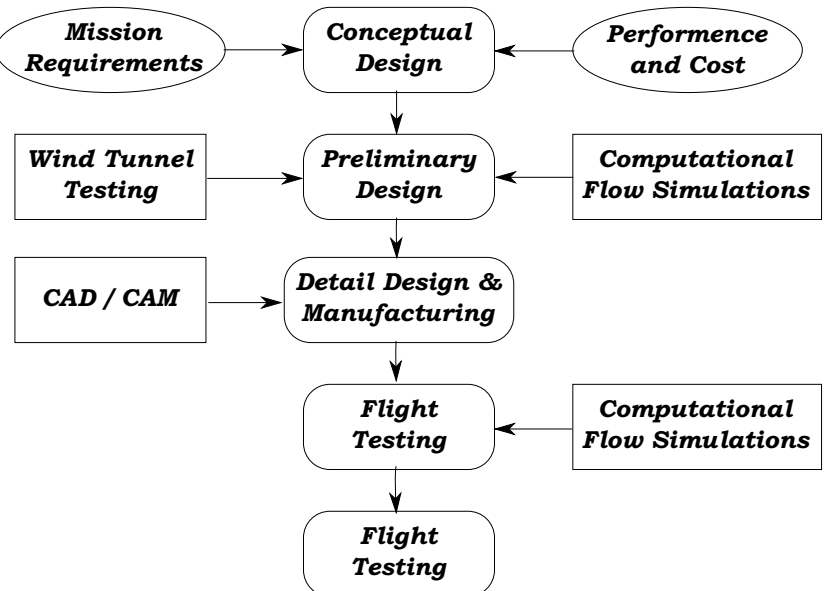

Figure 1.2 Aircraft development process (adapted from Brandt et. al.) [2]

provement. One such much needed enhancement is to be able to communicate between the analytical design tool and the 3D environment, i.e. CATIA ${ }^{\circledR}[3]$. Data communication between conceptual design programs has always been a major obstacle which now has a possible solution through this work, presently being done at Linköping University. A seamless connection appeals to the designer but it has to work both ways. There are a handful of existing software tools in the industry, at 
universities and research centres. Some have connections to CAD software but the connection is usually not seamless and even more rarely they work bi-directional [V]. Existing aircraft conceptual design tools are:

- $\operatorname{RDS}[4]$

- VSP [5]

- CDT $[6]$

- J2 Universal Tool Kit [7]

- ADS [8]

- Piano [9]

- RAGE [10]

- CEASIOM [11]

- PADLab [12]

\subsection{Aim}

The objective of this thesis is to create a framework for aircraft conceptual design and a database to have a flexible and close integration of CAD and supplementary tools. The geometry that is created using knowledge-based engineering techniques is to be subsequently propagated to preliminary design. The framework also attempts to address one tool vis one database concept.

RQ1 : Is it possible to have a tool for geometry definition and visualization with a high degree of design automation where the aircraft models can be gradually developed and also propagated from conceptual to preliminary design?

RQ2: What kind of framework is needed to exchange the data develop from the model from RQ1?

RQ3: What is the level of fidelity needed for the geometric model and how to implement it in a commercial CAD environment?

RQ4: Is it possible to create a water tight model by using the knowledgebased techniques to propagate the geometry to CFD? 


\subsection{Delimitations}

A brief overview of the knowledge-base and design automation is discussed, more focus is on the implementation of the same in this work. Explanations of different systems that were created in Hopsan and Dymola are not handled in this thesis. Tango design methodology and its implementation is not focused. An implementation of the XML integration process with RAPID and Tango is illustrated. Optimization frameworks that are used in this work hitherto are presented.

\subsection{Contribution}

This thesis proposes knowledge-based tool integration in aircraft conceptual design process. Knowledge-based geometry design tool RAPID is developed to help the designers realize the geometry of the aircraft at the earlier stages. The geometry created by using RAPID can be evolved to obtain a very high fidelity model/design. This facilitates for propagation of the geometry from conceptual design to preliminary design. The geometrical data can be stored in database and retrieved from the same. The thesis also explores different framework integrations in the conceptual aircraft design process.

"Scientists discover the world that exists; engineers create the world that never was." - Theodore von Karman 


\section{2 \\ Design \\ Methodology}

This section describes the methodology followed to create RAPID as knowledge based aircraft conceptual design tool.

\subsection{Knowledge-based Engineering and System}

Knowledge Based Engineering (KBE) is reusable information that exists in the specific method or form; this knowledge is reused either manually or automatically and the whole process of using this existing knowledge such that it adapts to the new environment is termed as Knowledge Based System (KBS) [13] [14]. Verhagen et. al. [15] have presented may definitions of KBE/KBS from several author and also showed example of $\mathrm{KBE}$ project results. KBE is a technology initiated by Concentra Corporation [16] and is in existence for a couple of decades. More and more people have seen the need [17] and also developed an application in aircraft design based on KBE [18]. Nowadays, most of the CAD software is embedded with this technology as packages e.g. knowledgeware in CATIA, knowledge fusion in NX [19] and expert system in Creo [20] (formerly pro-e).

The KBE/KBS automation is performed in CATIA using the Power Copy (PC) and the User Defined Feature (UDF) wherever necessary. VB scripts use the power copies and KP uses UDF to save the knowledge that is created for automation. PC or UDF is a set of features stacked together that can be reused at a later stage. A catalog is needed to 
store the location of the UDF. The KP algorithm script is written using the Engineering Knowledge Language (EKL) to control the UDF. UDF is used repeatedly to obtain a desired configuration. Further the UDF can be updated depending on the requirement and used accordingly. Creating the initial KBS is time consuming and the user needs to have some knowledge of the system in case of modifying it; however, once it is built there are numerous advantages of it and it could help the user build the necessary system faster and in less time. The Figure 2.1 [21] shows that by adopting KBE the time taken for the routine tasks can be minimized.

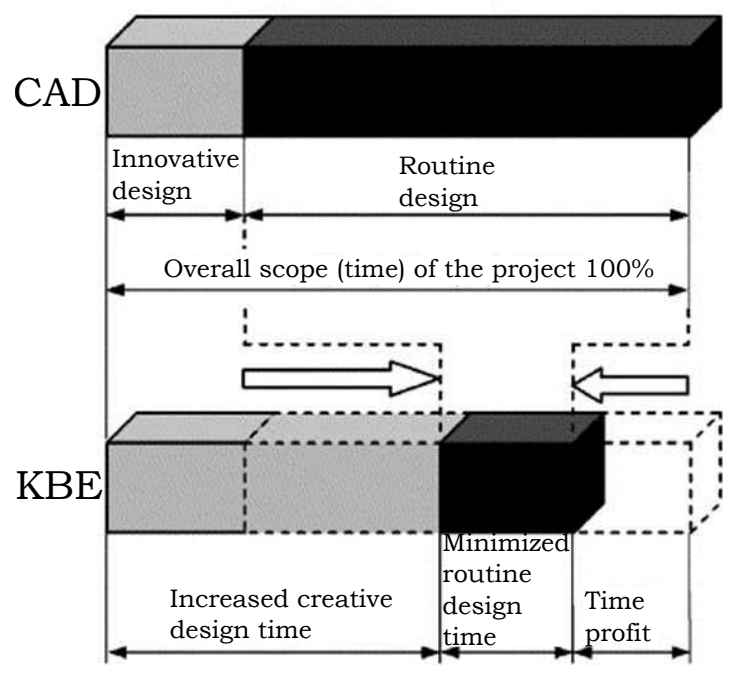

Figure 2.1 Design time by adopting KBE (adopted from Skarka) [21].

\subsection{Level of fidelity}

The frameworks similar to Paper [IV] and as shown in Figure 6.3 are CESIOM [22] by Royal Institute of Technology, design and engineering engine (DEE) by TU Delft [18] and DLR framework [23]. CESIOM also shows that the geometry created can be propagated to low and medium fidelity of CFD. All the above mentioned frameworks use the in-house tools developed by respective institutions/research organization. The main reason to use the commercial tools in this framework is to facilitate 
direct implementation of the tool framework in the industry. This will reduce the time for the industry implementing the framework as it need not redo all that has been done during the conceptual design.

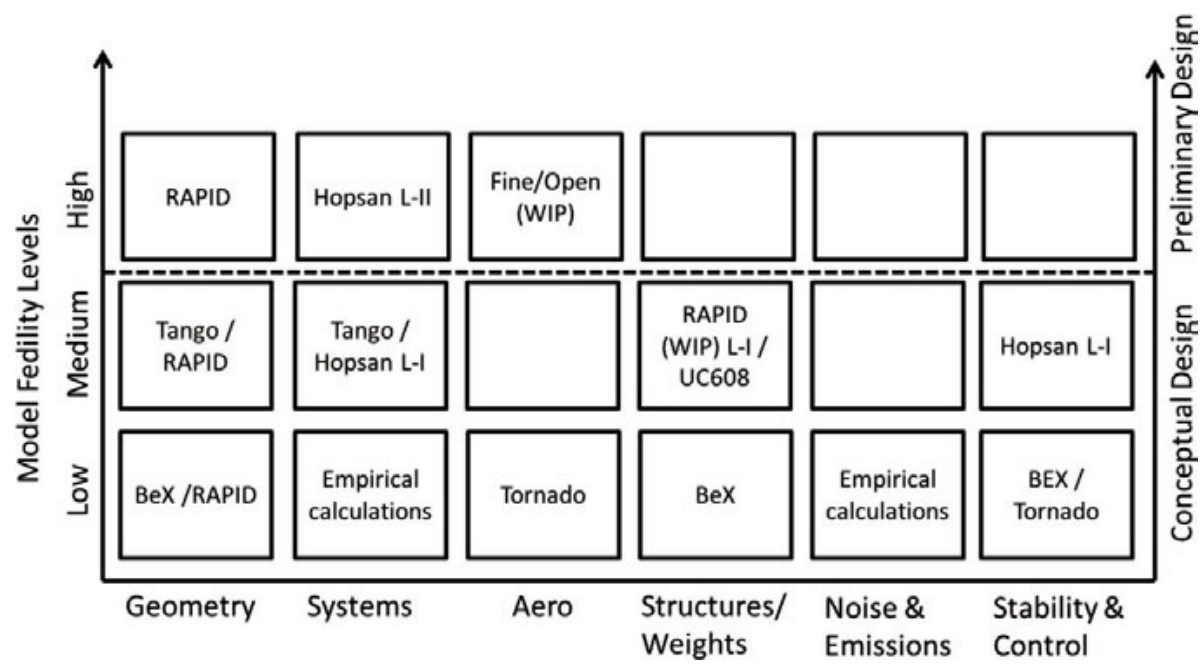

Figure 2.2 Model fidelity levels used in this framework (adapted and modified from Nickol) [24].

\subsection{Effective parametrization}

A good parameterization is to change the design according to designerrs intensions. In a KBS, there is a requisite for effective parameterization to obtain a good working system. In this circumstance, there can be different layers of parameterization involved in the entire aircraft (Figure 2.3). In RAPID, there are several layers of relational design, thus making it a complex model. Global references are the first set of parameters to initialize the positions of different objects such as fuselage, wing, horizontal tail, vertical tail, canard, engine etc. The second set of parameters gives the initial layout/shape of the aircraft, e.g. fuselage length, height and width that gives effective dimensions to different objects and forms the bottom-up approach in RAPID.

- Global references: Main positions of all the objects such as fuselage, wing, horizontal tail, vertical tail, canard and engine. 


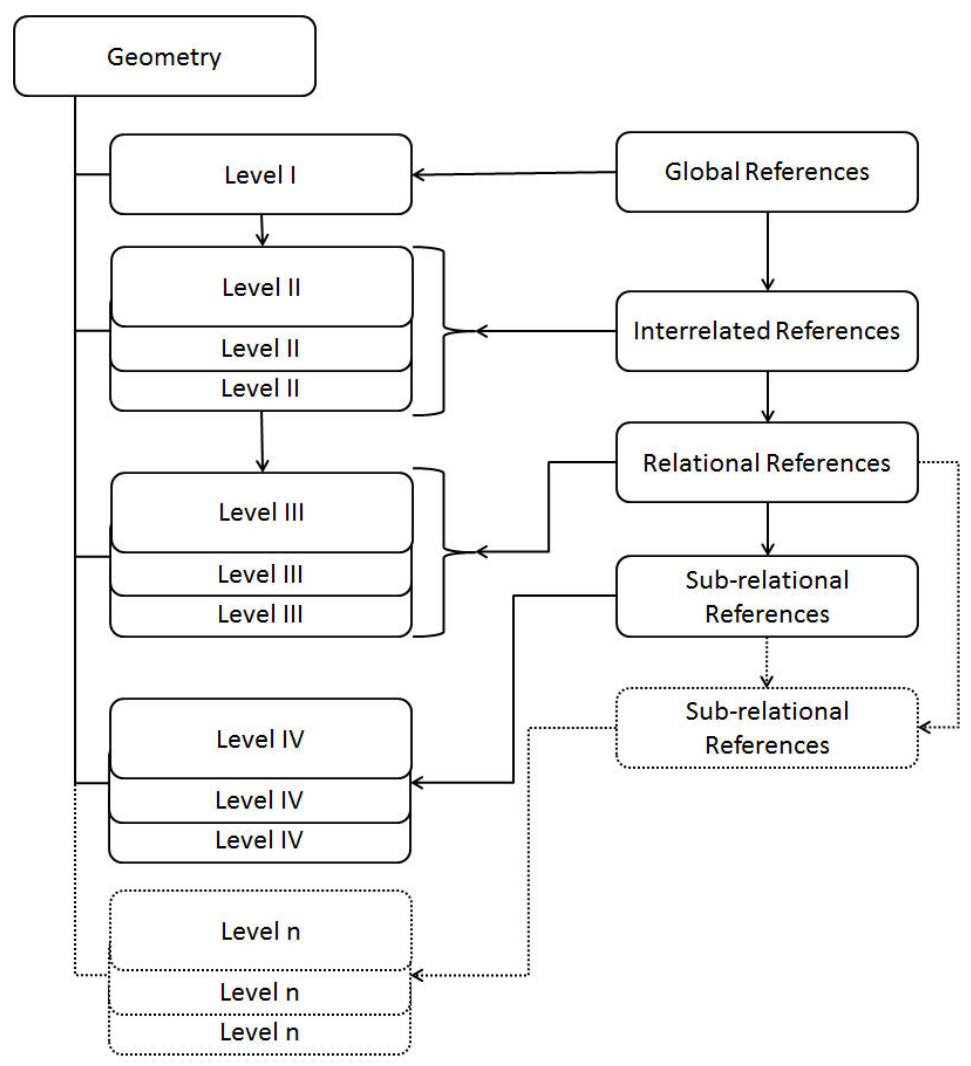

Figure 2.3 Design methodology applied in RAPID.

- Interrelated references: These are the references needed to size the aircraft. For example, the vertical tail reference area is dependent on the fuselage and its position from the origin; the horizontal tail and canard reference area depends mainly on their respective positions from global origin and the wing area. An overall twodimensional sketch is obtained after completion of this phase.

- Relational references: These are the references that help to give the shape / volume of the aircraft. For example, instantiation of number of fuselage frustums or number of wing partitions etc.

- Sub relational references: These the relational parameters that are available after instantiation of the instances of a number of frustums or number of wing parameters. There can be several layers of sub-relational references depending upon where the instances 
follow.

\subsubsection{Parametrization Example}

To create " $\mathrm{n}$ " number of points with a reference from the given coordinate system, there is a necessity of " $3 \mathrm{n}$ " parameters even if all the points are to be of the same length in Z-direction. If all the four points used to create a rectangle as shown in Figure 2.4 are created with a reference from the given coordinate system then twelve parameters are needed. To reduce the number of parameters an efficient parametrization is necessary, i.e., relational parametrization. The above mentioned example is modified for the efficient parametrization by using only less than half of the parameters needed.

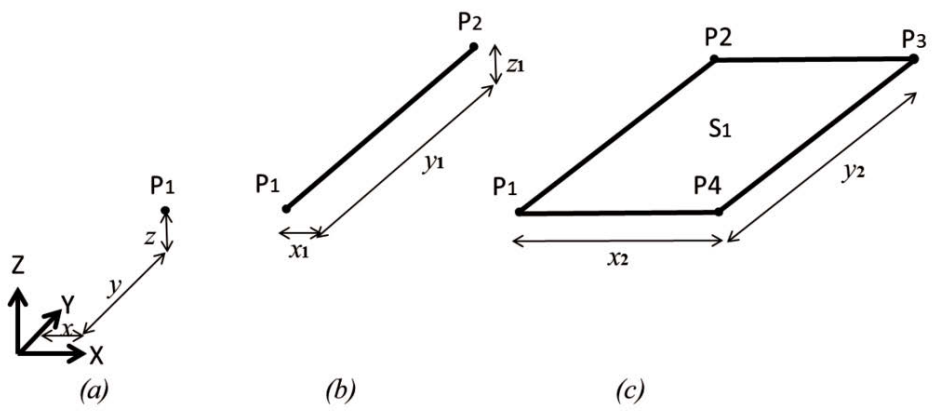

Figure 2.4 Parametrization Example

To effectively create a point $P_{1}$ from a given coordinate system three coordinates $(x, y, z)$ are required. Point $P_{2}$ is created from point $P_{1}$ along the $\mathrm{Y}$-axis with a distance $\left(y_{1}\right)$, by doing so reduces the number of variable parameters that need to be defined to one parameter. Points $P_{3}$ and $P_{4}$ are created from points $P_{2}$ and $P_{1}$ respectively, along the $\mathrm{X}$-axis with a distance $\left(x_{2}\right)$. In total the number of parameters needed from the relational parametrization is only five. An extra two more parameters are needed to modify the shape of the rectangle to obtain any quadrilateral. In Chapter 5, a practical application of the parameterization is presented for better understanding of effective parameterization. From Table 5.3 it can be observed that the robustness of the kinked wing have increased approximately $30 \%$ by effective parameterization. Kulfan [25] presents parametric geometrical method that can be applied to obtain wide rage of geometry objects. 
"To know what you know and what you do not know, that is true knowledge." - Confucius 


\section{RAPID - Robust Aircraft Parametric Interactive Design}

RAPID (Figure 3.1) is a geometry oriented design tool used in the framework of aircraft conceptual design. The core incentive to use CATIA is to allow the geometry propagation from conceptual design to preliminary design. Knowledge Pattern (KP) and Visual Basic (VB) embedded in CATIA are used for automation at necessary stages. There are three ways the user can design the aircraft in RAPID.

- By modifying the existing model after loading from XML data library (Figure 3.3).

- By updating the model from the Sizing Excel (Figure 3.2).

- By bottom-up design approach (Figure 3.5).

The bottom-up design approach can be employed in RAPID to design from scratch or the user can load the existing aircraft model from the XML data library. The user begins by modifying the fuselage curves according to design requirements and later adapting the wing. The empennage is automatically sized depending on the given fuselage parameters and wing parameters. The adaptability of the model helps to obtain different aircraft configurations.(Figure 3.4) 


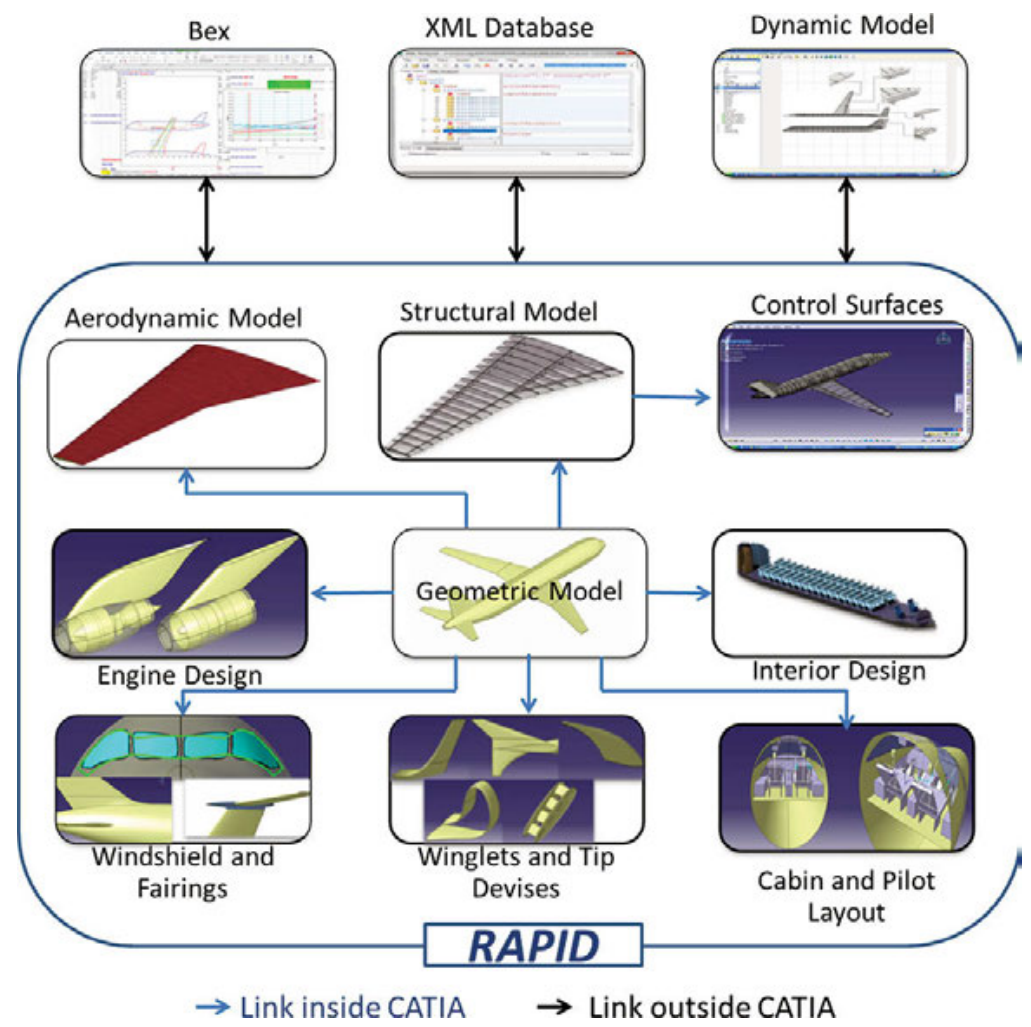

Figure 3.1 RAPID Tool.

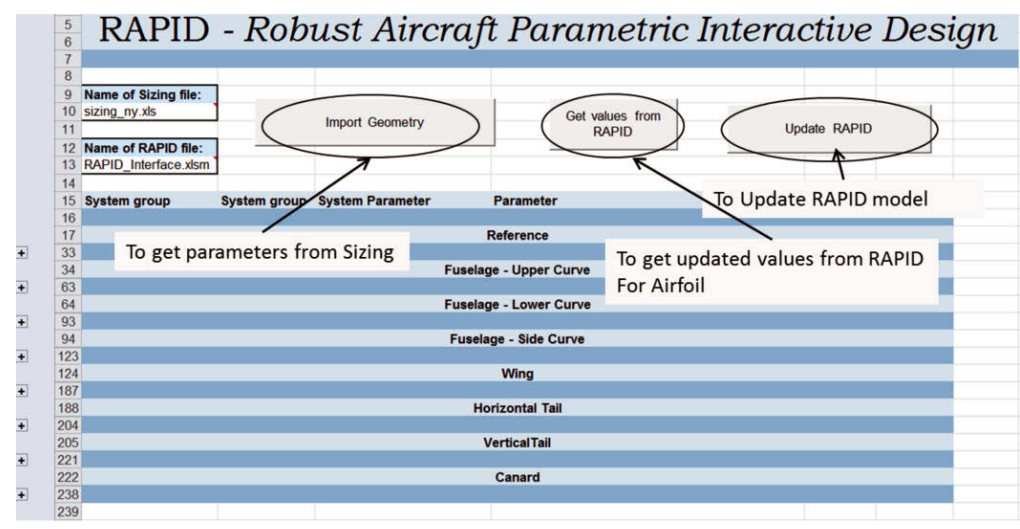

Figure 3.2 User interface for Geometry. 


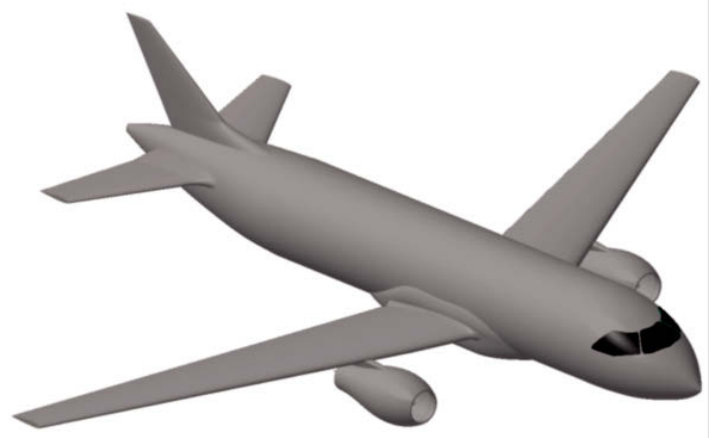

Figure 3.3 Example of Civil transport aircraft geometry loaded from database.
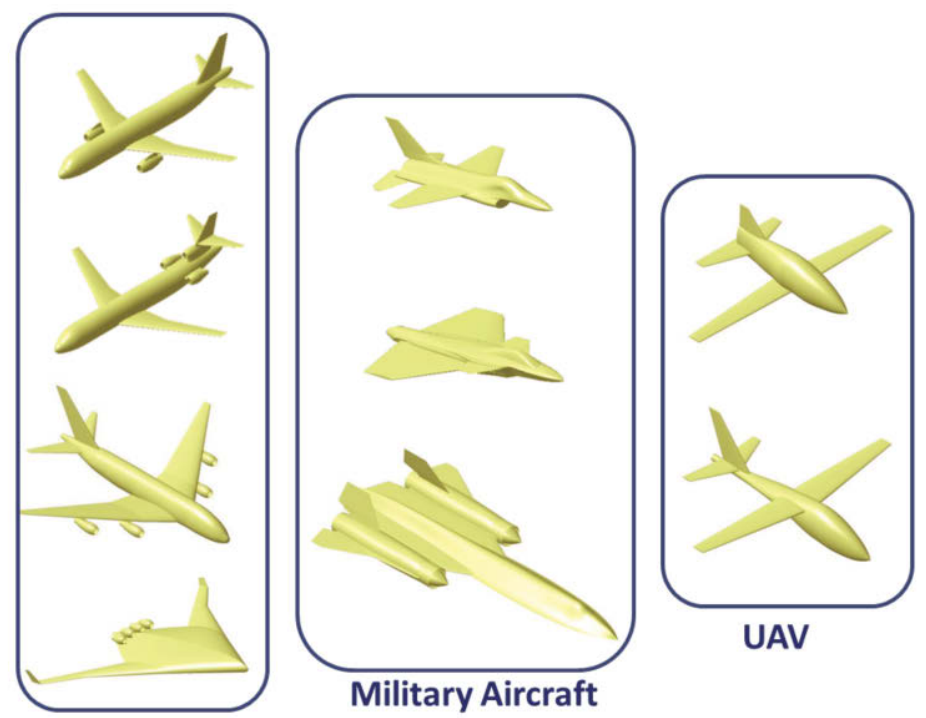

Civil Aircraft

Figure 3.4 Different aircraft configurations of geometry model RAPID. 


\subsection{Geometry Model}

After the initial setup of the wireframe model of the aircraft, a more detailed geometry can be developed (Figure 3.3). The user chooses the number of frustums needed for the fuselage and the number of partitions needed for wing, empennage and canard depending on the requirement.

\subsubsection{Fuselage Geometry Description}

The Fuselage wireframe is composed of four supporting splines; they are upper curve, bottom curve, side curve and center curve (Figure 3.5). The splines are created in desired manner which are then taken as reference for the instantiation of frustums. A frustum is formed by two Bezier curves joined by a surface. Bezier curves are parametric and can be modified to get desired cross-section at each frustum (Figure 3.6).
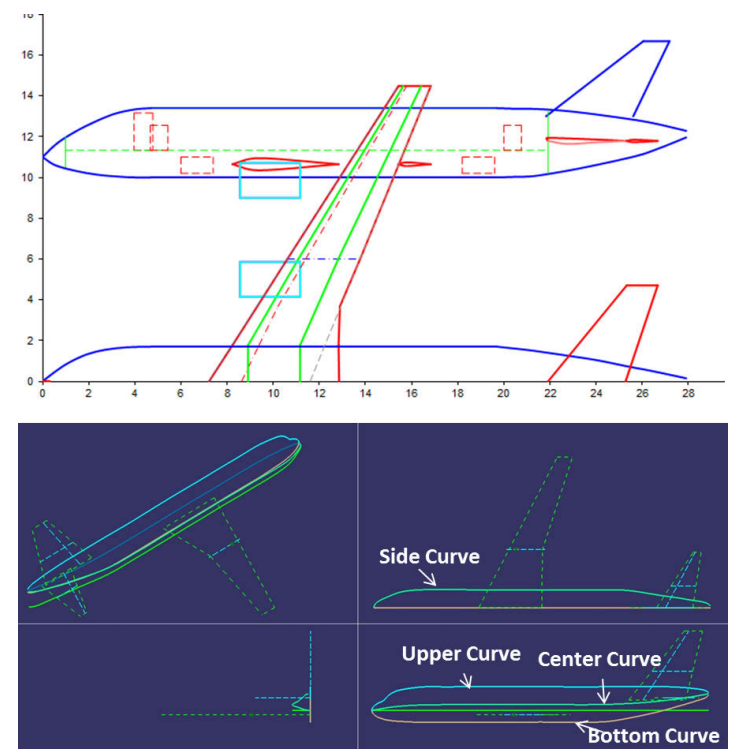

Figure 3.5 Fuselage curves in Sizing Excel (Top); Fuselage curves in RAPID (Bottom).

\section{Establishing global fuselage geometry}

$$
f u=f\left(S_{p}, L_{f}, W_{f}, H_{f}, C_{s}\right)
$$




$$
\begin{aligned}
& \mid S_{p}(Z)=\sum_{n=0}^{n} f_{i}(z) P_{j} \\
& \quad j=[2, n) ; P_{0}^{x}=0 ; P_{n}^{x}=L_{f} \\
& \quad n_{x}-1<n_{x}<n_{x}+1 \\
& \quad \triangle x=\frac{L_{f}}{n-1} \\
& \quad n \in \mathbb{N}
\end{aligned}
$$

A quarter of the fuselage cross-segment is portrayed by third-order Bezier curve. The angle is measured from the horizontal line for "upper line" and "lower line" and angle is measured from the vertical line for "side upper line" and "side lower line". The Points 1, 4 and 7 shown in Figure 3.6 are the intersection points with the fuselage curves while points $2,3,5$ and 6 are positioned along the respective lines as a fraction.

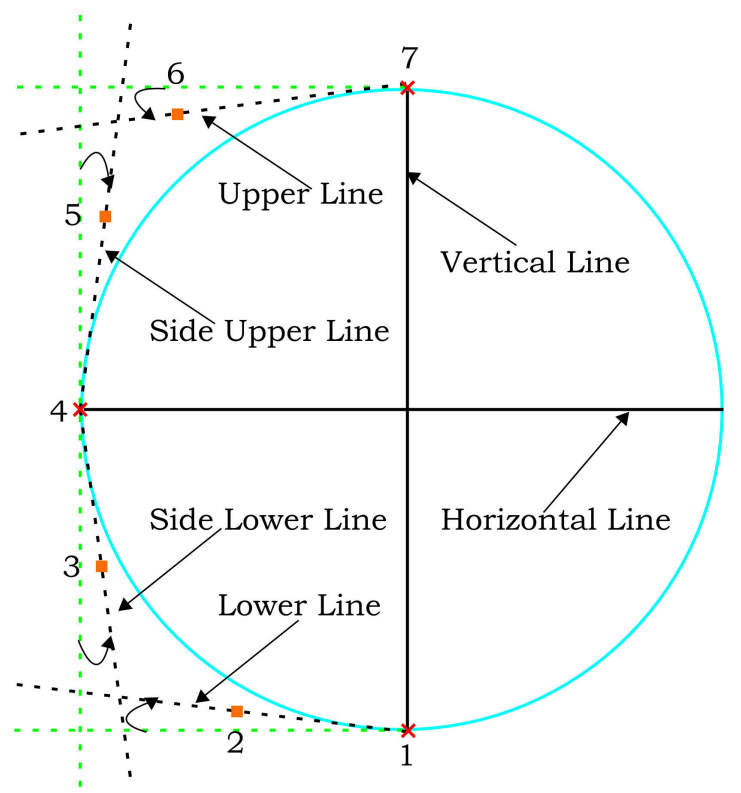

Figure 3.6 Description of RAPID fuselage Crosssection [V]

\section{Establishing fuselage cross-section}

$$
C_{s}^{i}:=f(p, \alpha)
$$




$$
\begin{aligned}
& \mid i=1,1, \ldots n \\
& n \in \mathbb{N} \\
& {\left[p_{1}^{i}, p_{4}^{i}, p_{7}^{i}\right]:=f\left(C_{u}, C_{l}, C_{c}, C_{s}^{i}\right)} \\
& {\left[p_{2}^{i}, p_{3}^{i}, p_{5}^{i}, p_{6}^{i}\right] \in[0,1]} \\
& {\left[\alpha^{i}{ }_{p_{2}}, \alpha^{i}{ }_{p_{3}}, \alpha^{i}{ }_{p_{5}}, \alpha^{i}{ }_{p_{6}}\right] \in\left[0, \frac{\pi}{2}\right]}
\end{aligned}
$$

\subsubsection{Wing Geometry Definition}

Wing wireframe is generated by taking the reference area, taper ratio and aspect ratio as reference. The user has an option to choose the angle either from leading edge or $25 \%$ root chord to obtain trapezoidal wing area (shown in dotted line in Figure 3.7). There also exists another reference area method to choose from such as Double delta, Gross Method and Wimpress Method. The RAPID area method uses the trapezoid area as a reference, after instantiating required number of partitions the chord at each airfoil can be modified to obtain different wing shape as shown in Figure 3.7. The final wing area is obtained by the sum of all the instantiated partitions.

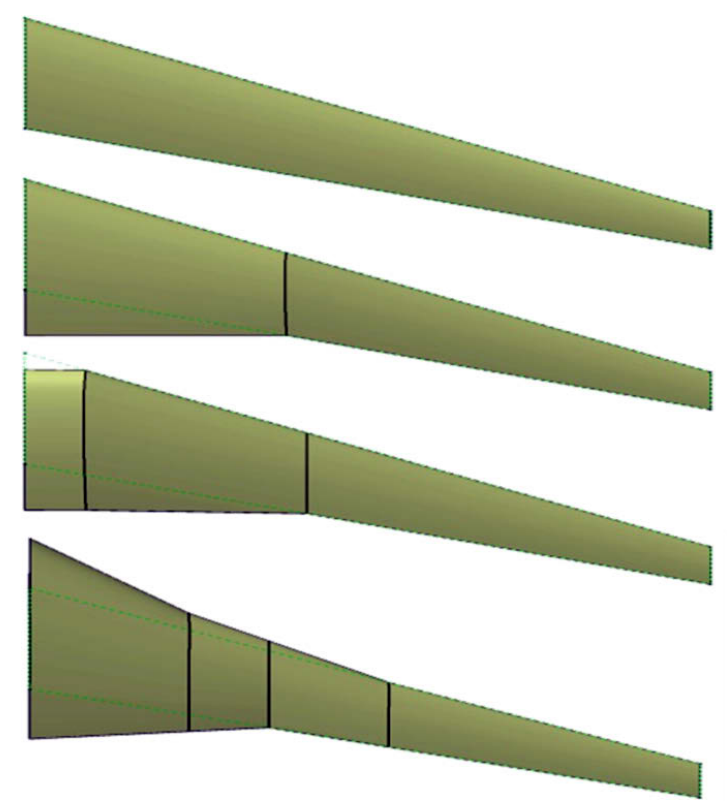

Figure 3.7 Different wing shapes modified after instantiation of partitions. 


\section{Establishing wing geometry}

$$
\begin{aligned}
w= & f\left(S, A_{R}, \lambda_{i}, \wedge_{i}, k_{j}, w_{p}\right) \\
& \mid i=1,2, \ldots n \\
& j=0,1,2 \ldots n-1 \\
& n \in \mathbb{N}
\end{aligned}
$$

Each partition is made up of two airfoils joined by a surface. The airfoils are generated using third-order Bezier curves. The same partition template is used for horizontal tail, vertical tail and canard. Since the airfoil is parametrically defined, it can be used to obtain " $\mathrm{N}$ " number of airfoil shapes [26]. Different types of winglets and wing tip devices can be chosen (Figure 3.8). The wireframe is first instantiated and later number of wing partitions are instantiated. The projected areas of each partition are summed up automatically to give the final area of the wing and winglets.

\section{Establishing wing partition}

$$
\begin{aligned}
& w_{p}^{i}:=f(B(t), \Gamma, \phi, \theta) \\
& \quad \mid i=1,2, \ldots n \\
& n \in \mathbb{N} \\
& B(t)=(1-t)^{3} P_{0}+3(1-t)^{2} t P_{1}+3(1-t) t^{2} P_{2}+t^{3} P_{3} \\
& \quad t \in[0,1] \\
& \quad\left[\Gamma^{i}, \phi^{i}, \theta^{i}\right] \in\left[-\frac{\pi}{2}, \frac{\pi}{2}\right]
\end{aligned}
$$

\subsubsection{Engine Design}

Two types of engines(Figure 3.9) turbofan and turbojet can be sized in RAPID. Thrust, Specific fuel consumption (SFC), Weight, Length, Diameter and By-pass ratio are the key parameters that size the engine. Turbofan engine is sized to suit commercial aircraft engine dimensions 


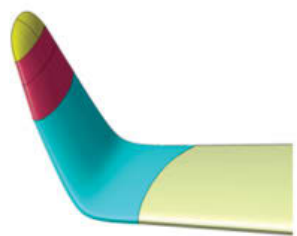

Blended

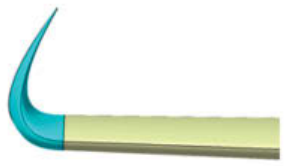

Upswept

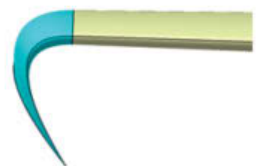

Drooped

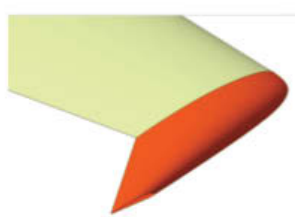

Raked

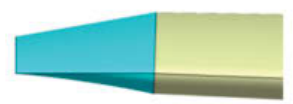

Hoerner

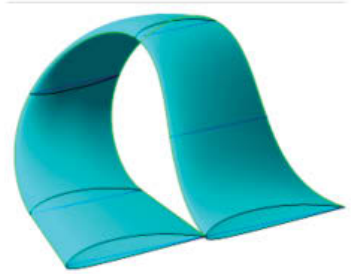

Spiroid

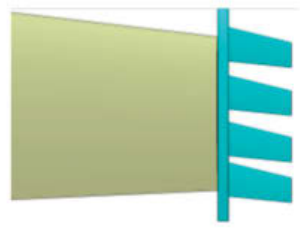

Wing Grid

Figure 3.8 Different types of Winglets [27].

with a bypass ratio from 3 to 20 ; turbojet engine to suit the dimensions of business jets and military engines with no after burner engines with a bypass ratio from 0.1 to 15 .

Nacelle geometry design depends on the type of engine and various parameters that can be changed to obtain the desired contour. Mixedflow and separate-jet are two kinds of nacelles available; straight and smooth pylon types can be chosen. Nacelle design depends on the type of engine and various parameters can be changed to obtain the desired contour. Pylon is designed in contest with nacelle, start and end values are changed accordingly. Air inlet and duct for military application is a work in progress. 


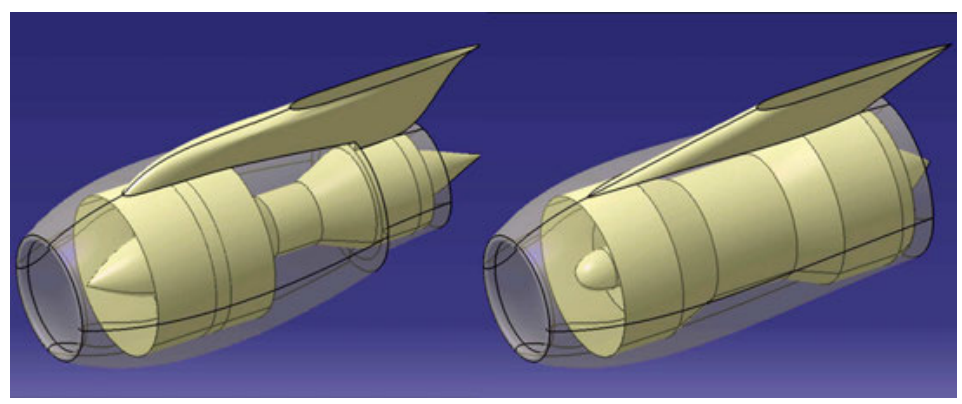

Figure 3.9 Turbofan (left) and turbojet engine (right) $[V]$.

\subsection{Interior Design}

Comfort is the privilege that a passenger craves for while travelling. Aircraft Interiors is a major part of the Aircraft Design process. Cabin space has to be utilized in a intelligent fashion using most of the space, identifying the comfort factors for passenger, able to accommodate the maximum number of passengers according to the requirement. FAR 25 rules [28] have been implemented in cabin design.

\subsubsection{Cockpit Design}

The cockpit design consists of windshield design, cockpit layout and ergonomic study. Flat panels and blended windshield can be generated. The wing shield uses the visibility pattern as the wireframe and later number of panels can be instantiated shown in Figure 3.10.
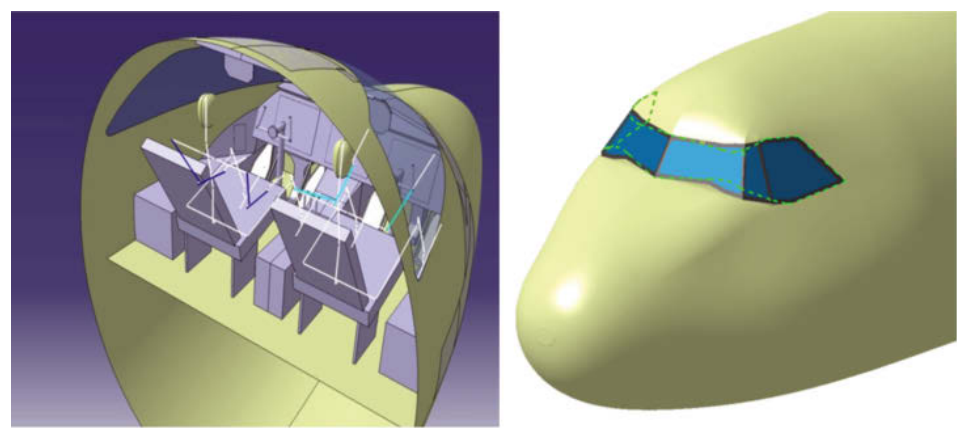

Figure 3.10 Cockpit and Windshield model [29] [VI]. 


\subsubsection{Cabin Layout}

Seating layout, doors, windows, galley, lavatory and containers can be configured from the cabin interior layout. FAR rules have been applied to all the entities listed above. The overall length of the cabin needed is computed and the user will know the cabin length available at all times. Depending on the number of passengers; type of galley, number of galleys, number of trolleys in each galley and number of food trays needed are computed. The weights of first class, business class and economy seats are computed after instantiation.
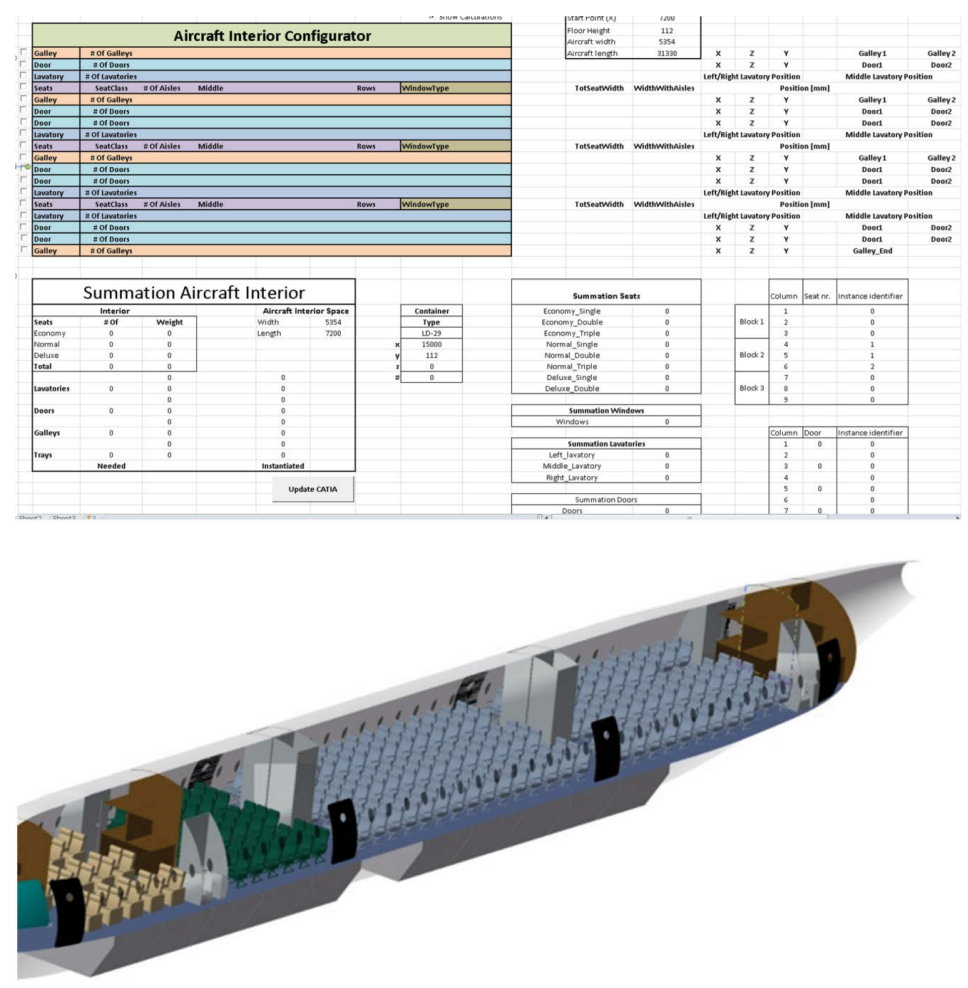

Figure 3.11 Cabin Layout Interface and Cabin Interior.

"Design is not just what it looks like and feels like. Design is how it works." - Steve Jobs 


\section{4}

\section{Data Management}

Data created in RAPID or Tango can be delivered in the "eXtensible Markup Language" (XML) format [30]. XML allows applications to represent electronic documents or text data in an easy to understand and transferable format between programs. XML is made up of markup tags and data to represent the information. An XML forms a tree structure, this makes it easy to retrieve data and find relationship between different information represented in the XML.

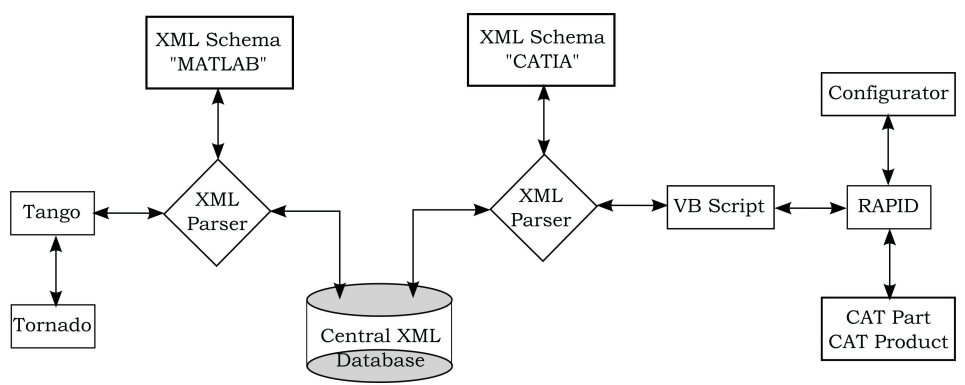

Figure 4.1 XML data flow between the two main applications RAPID and TANGO with the help of XSLT.

Transformation of XML document is performed by XSL Transformations (XSLT). XSLT uses XPath language to navigate in XML documents. It can serve for complex translations such as element and attribute editing (add, remove, replace), rearrangement, sorting, perform tests and make decisions [30].

The functional approach (Figure 4.1) is different in RAPID and Tango as the fundamental design approach varies in CAD and technical com- 


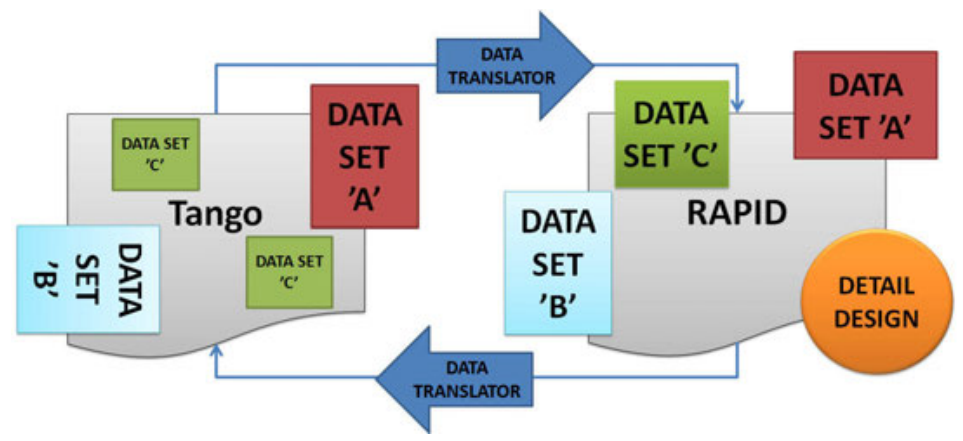

Figure 4.2 Data communication with different subsets of geometry.

puting/programing language. Data created is translated between the programs using the data translator. In Figure 4.2 dataset 'A' of the initial geometry representation (Figure 3.5) is available in both programs. Later dataset ' $\mathrm{B}$ ' is added in Tango and is updated in RAPID. It is to note that dataset ' $\mathrm{C}$ ' created in RAPID is split into two subsets in Tango; for example:- wing and the engine housing are in the same geometrical product in RAPID but this is split in Tango as geometrical and functional subsets. Detail design or design add-ons to the geometry are not updated in Tango.

\subsection{RAPID XML Export}

Excel Visual Basic for Applications (VBA) [31] is used to configure the CATIA parameter or geometrical sets and generates into an XML. The following steps are implemented in creating XML from RAPID

- Configuration of Parameter and Geometric sets through Excel: Configuring the parameters through Excel will reduce the effort of adding changes to the code whenever a new parameter/geometrical set need to be added to the XML. The configuration contains three main parts in Excel:

1. Parameter String: represents the parameter set/geometrical set from CATIA. All the parameters within the parameter set will be made as XML. Example: "reference $\backslash$ inputparameters" (Figure 4.3) 
2. Parameter Array: used for making XML tags to the parameter sets or geometrical sets and parameters. Depending on the depth of the XML tree, number of values in the Array String is needed. Example: XML node - <part name= reference>. (Figure 4.3)

3. Array List: Needed to put together parameter sets from the same part into one list. Each part will have one corresponding Array List. Example: "fuselage inputParameters" and "fuselage \instantiatedGeometry" should come under the same part fuselage in XML. So they have same array list Name fuselageList. (Figure 4.3)

- List "Hash" [32], is a dictionary object (key, value) that is used in the code because of the Array List column that comes from Excel. The Array List column gives only Array List Names but does not create them. This handles the grouping of the parameter sets with the same Array List into one list instead of separate ones. For the first time an array list for a given name is created, thereafter it does not create a new array list if the name already exists.

- Value Parsing: To parse the CATIA parameters and translate them to XML, two loops are used: The outer loop runs through all the parameter lists from CATIA and inner loop, runs through the parameter list of the Excel sheet. Strings from CATIA are compared with strings from Excel and the matching strings from CATIA are created as XML document.

- Writing into XML using DOM Object: For efficient XML editing, Microsoft XML DOM object is used in the VBA section to translate the parameter/geometric sets into XML. The DOM object creates the XML file and takes care of the formatting and structure. This data set tree related access method also helps in modifying the XML without any hassles or cumbersome coding.

- Spline from CATIA to XML: The spline in CATIA cannot be handled similar to that of the rest of the parameter/geometrical sets, as the coordinates of the points in the splines are not available directly in CATIA tree. The geometrical set in CATIA is taken as a parameter string from Excel, where the sketches are added. One array each is used to store the $\mathrm{x}, \mathrm{y}, \mathrm{z}$ coordinates of 
the spline control points from the exchange Curves. Example: "fuselage $\backslash$ exchangeCurves" (Figure 4.3)

- Finally the XML DOM object is written to file and saved as XML.

\subsection{XML to RAPID Import}

The following steps are performed to read XML to RAPID:

- Parsing the XML using DOM object: The XML file is loaded into a DOM Object. This DOM object is parsed for the required information and tags.

- Recursive Function to get child nodes: The values of parameters that need to be updated into CATIA are stored in the child nodes with a value tag. A recursive function is used to get all the child nodes with a value tag from the XML and the corresponding text in these nodes. These texts are the new values to be updated.

- Constructing the Parameter Strings to be updated: The parameter string that needs to be updated in CATIA needs to be constructed; a recursive function is used to get the parent nodes for the child nodes with the value tag. These parent node tags are appended along with " \" to form the string.

- Spline from XML to CATIA: The existing spline is deleted first. The spline values in XML are stored as Control Points with $\mathrm{x}$ - and $y$-value Nodes (xvalue, yvalue). These Nodes are recursively read using DOM object. Using these $\mathrm{x} / \mathrm{y}$ points, new Control Points are formed and then a new spline is created in CATIA.

- Updating CATIA: The parameter Strings along with the corresponding values are updated in the CATIA using VBA-CATIA Functions. 


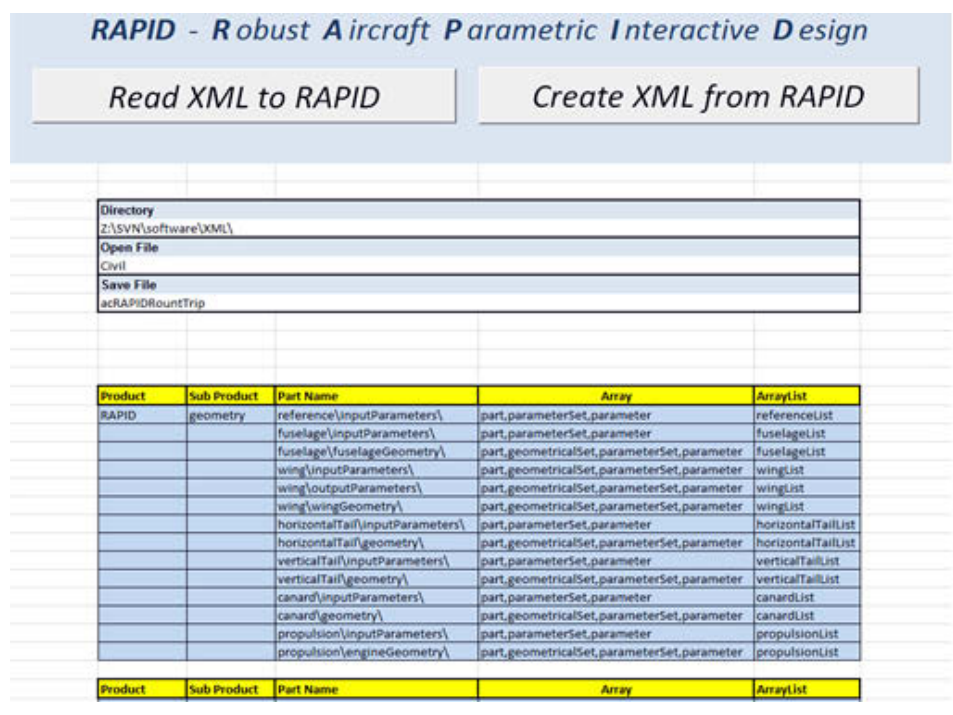

Figure 4.3 The RAPID-XML Interface.

\subsection{Tango XML}

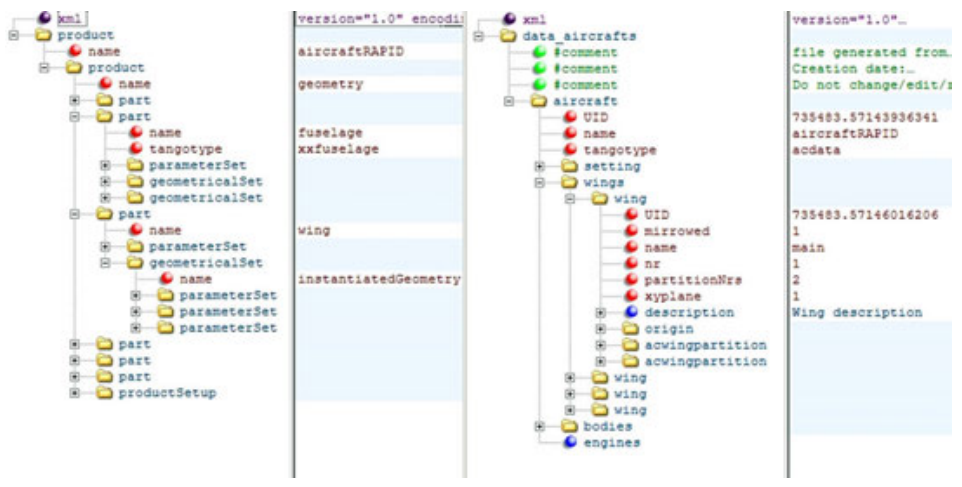

Figure 4.4 Data Structure adapted towards the tools needs (Right side: Tango XML, Left Side: RAPID XML.

Tango uses the inbuilt Matlab Java DOM application classes for XML data rendering. The data is handled via object oriented geometrical or functional classes where every class has included class-related XML parsing functionalities. This method allows for greater flexibility and fast replacement or appending of new classes.

The elementary classes are product $\backslash$ geometry related (e.g., wing and 
underlying wing partition class), whereas the higher level classes are product-functional (system) related (e.g., fuel system, primary flight control system). This class reference transition within the dataset makes it necessary to work with part pointers in order to link the functional classes with its related geometrical properties in the geometry related classes; Examples are the control surfaces (geo. def.) that are part of the PFCS (sys. def.) and the wing fuel tanks (geo. def.) that are part of the fuel/propulsion system (sys. def.). By these links, the strict hierarchal XML (tree) data structure becomes extended by cross-branch couplings, described by the part pointers. XML document of both Tango and RAPID is presented in Figure 4.4

"Eventually everything connects - people, ideas, objects. The quality of the connections is the key to quality per se." - Charles Eames 


\section{5 \\ Design Space}

Information is congregated in the product from the conceptual design to detail design; in this case the RAPID/Tango model saves a lot of data about the aircraft. The initial design defined by the skeleton in Figure 3.5 is a design point in the design space obtained from the initial requirements.

Table 5.1 Number of parameters for aircrafts in Figure 7.1 and Figure 7.2

\begin{tabular}{|l|l|l|l|l|}
\hline CAD Parts & \multicolumn{2}{|c|}{$\begin{array}{l}\text { Number of Parame- } \\
\text { ters }\end{array}$} & $\begin{array}{l}\text { Total number of } \\
\text { Parameters }\end{array}$ \\
\hline Wireframe & Surfaces & $\begin{array}{l}\text { Civil } \\
\text { Aircraft }\end{array}$ & $\begin{array}{l}\text { Military } \\
\text { Aircraft }\end{array}$ \\
\hline Fuselage & 93 & 108 & 201 & 201 \\
\hline Wing & 93 & 108 & 201 & 201 \\
\hline $\begin{array}{l}\text { Horizontal } \\
\text { Tail }\end{array}$ & 18 & 46 & 64 & 64 \\
\hline $\begin{array}{l}\text { Vertical } \\
\text { Tail }\end{array}$ & 18 & 46 & 64 & 64 \\
\hline Canard & 18 & 46 & - & 64 \\
\hline $\begin{array}{l}\text { Engine } \\
\text { Civil }\end{array}$ & 11 & 34 & 45 & - \\
\hline $\begin{array}{l}\text { Engine } \\
\text { Military }\end{array}$ & 11 & 50 & - & 66 \\
\hline Total number of parameters & & 464 & 549 \\
\hline
\end{tabular}

To measure the robustness and flexibility of the geometry, three tests were conducted on the same kinked wing of civil aircraft (Figure 7.1). 
modeFRONTIER ${ }^{\circledR}[33]$ was used to compute different designs.

Table 5.2 Wing test case setup

\begin{tabular}{|l|l|l|l|l|l|l|l|}
\hline \multicolumn{2}{|c|}{} & \multicolumn{2}{|l|}{ Wing Test 1 } & \multicolumn{2}{l|}{ Wing Test 2 } & \multicolumn{2}{l|}{ Wing Test 3 } \\
\hline $\begin{array}{l}\text { Design } \\
\text { Pa- } \\
\text { rame- } \\
\text { ter }\end{array}$ & Ref & Min & Max & Min & Max & Min & Max \\
\hline AR & 9.71 & 4.71 & 14.71 & 0.7147 & 18.71 & 0.7147 & 18.71 \\
\hline $\begin{array}{l}\text { TR } \\
\text { Outer } \\
\text { Wing }\end{array}$ & 0.14 & 0.09 & 0.19 & 0.04 & 0.24 & 0.04 & 0.24 \\
\hline $\begin{array}{l}\text { TR } \\
\text { Outer } \\
\text { Wing }\end{array}$ & 0.14 & 0.09 & 0.19 & 0.04 & 0.24 & 0.04 & 0.24 \\
\hline $\begin{array}{l}\text { TR } \\
\text { Inner } \\
\text { Wing }\end{array}$ & 0.53 & 0.13 & 0.93 & 0.03 & 1.03 & 0.03 & 1.03 \\
\hline $\begin{array}{l}\text { kink } \\
\text { Posi- } \\
\text { tion }\end{array}$ & 6407 & 5907 & 6907 & 5407 & 7407 & 0.3212 & 0.4407 \\
\hline $\begin{array}{l}\text { wing } \\
\text { Area }\end{array}$ & 116.32 & 66.32 & 166.32 & 16.32 & 216.32 & 16.32 & 216.32 \\
\hline $\begin{array}{l}\text { sweep } \\
\text { Inner } \\
\text { Wing }\end{array}$ & 21.43 & -28.57 & 71.43 & -43.57 & 86.43 & -43.57 & 86.43 \\
\hline $\begin{array}{l}\text { sweep } \\
\text { Outer } \\
\text { Wing }\end{array}$ & 21.43 & -28.57 & 71.43 & -43.57 & 86.43 & -43.57 & 86.43 \\
\hline
\end{tabular}

Design of experiments was created using Latin Hypercube sampling to obtain values that are relatively uniformly distributed for each input parameter as shown in Table 5.2. Robustness and flexibility of the design are also computed [34] as shown in Table 5.3. In "Wing Test 2" the designs have failed because the kink position is placed outside the wing for minimum values of Aspect Ratio (AR) and wingArea (Table 5.2). The Robustness in "Wing Test 2" is affected by poor parameterization of the kink position, to improve robustness of the model kink position could be given as a ratio of the span of the wing. "Wing Test 3" was 
conducted with the same span of the wing as in "Wing Test 2", so that the design space is the same. It can be seen from Table 5.3 for "Wing Test 3" the flexibility and robustness of the model has increased. There were only 31 of 2000 designs that have failed in this case. It has been observed that the failure of these designs occurred for values of "sweepInnerWing" and "sweepInnerWing", at angles closer to 85 degrees and above. The robustness of the model increase considerably by having the kink position a ratio of the span.

Table 5.3 Robustness and flexibility for a kinked wing

\begin{tabular}{|l|l|l|l|l|l|}
\hline & $\begin{array}{l}\text { Number } \\
\text { of Designs }\end{array}$ & $\begin{array}{l}\text { Number of } \\
\text { Parameters }\end{array}$ & $\begin{array}{l}\text { Design } \\
\text { Space }\end{array}$ & $\begin{array}{l}\text { Ro- } \\
\text { bust- } \\
\text { ness }\end{array}$ & $\begin{array}{l}\text { Flex- } \\
\text { ibil- } \\
\text { ity }\end{array}$ \\
\hline $\begin{array}{l}\text { Wing } \\
\text { Test 1 }\end{array}$ & 1000 & 7 & 13.59 & 1 & 13.59 \\
\hline $\begin{array}{l}\text { Wing } \\
\text { Test 2 }\end{array}$ & 2000 & 7 & 19.33 & 0.751 & 14.52 \\
\hline $\begin{array}{l}\text { Wing } \\
\text { Test 3 }\end{array}$ & 2000 & 7 & 19.33 & 0.985 & 19.04 \\
\hline
\end{tabular}

Design space in Table 5.3 is affected by the number of design parameters involved in the process; it would become very large once all the parameters in Table 5.1 are used to compute the design space. The normalized sensitivity matrix is shown in Table 5.4, wingArea and AR are the two parameters that mainly affect the system characteristics or output parameters of the wing.

Table 5.4 Normalized Sensitivity Matrix

\begin{tabular}{|l|l|l|l|l|l|}
\hline & \multicolumn{5}{|c|}{ Design Parameters } \\
\hline $\begin{array}{l}\text { System } \\
\text { Character- } \\
\text { istics }\end{array}$ & $\begin{array}{l}\text { Aspect } \\
\text { Ratio }\end{array}$ & $\begin{array}{l}\text { TR } \\
\text { Outer } \\
\text { Wing }\end{array}$ & $\begin{array}{l}\text { TR } \\
\text { Inner } \\
\text { Wing }\end{array}$ & $\begin{array}{l}\text { kink } \\
\text { Posi- } \\
\text { tion }\end{array}$ & $\begin{array}{l}\text { wing } \\
\text { Area }\end{array}$ \\
\hline $\begin{array}{l}\text { middle- } \\
\text { Chord }\end{array}$ & -0.24 & -0.10 & 0.00 & -0.37 & 0.61 \\
\hline rootChord & -0.24 & -0.10 & -1.01 & -0.38 & 0.61 \\
\hline tipChord & -0.50 & 0.88 & 0.00 & 0.00 & 0.50 \\
\hline
\end{tabular}

In RAPID, as the user has different reference area methods, this might be difficult to pick the correct method. A number of parameters are 
accessible for the user in order to obtain various configurations. This might lead to a geometry that is over-defined or has a lot of parameters to play with.

"We can't solve problems by using the same kind of thinking we used when we created them." - Albert Einstein 


\section{6 \\ Optimization Frameworks}

This section presents the multidisciplinary design and optimization frameworks that are included in this thesis.

\subsection{Framework with adapted scripts for optimiza- tion}

The framework presented in Paper [I] integration has been made between CATIA, Tornado and Dymola by a customized interfaces to provide an automatic interaction between these disciplines. The user interface connecting CATIA control surfaces is as shown in Figure 6.1. Parameters such as root chord, tip chord and length of the control surface are modified and updated. Inboard flap, Outboard flap and aileron can be updated to both high wing and low wing aircraft, while the elevator can be updated with respect to both T- tail and conventional tail configurations. The values of the above mentioned components can be sent to Tornado to update the aerodynamic model. The Workbook is divided into the following Sheets:

- Design Parameter sheet for all models are connected and used in the proposed framework. The design parameters allow users to modify the models without having to enter the tools that are used for their construction.

- Force Parameters sheet contains forces obtained from the Aerody- 
namic model and are updated in the Dynamic model.

- Mass properties sheet is used to obtain the mass properties from CATIA and update them in the Dynamic model.

The Dymola model used in this framework simulates the dynamics of the control surfaces and computes the force needed to extend the flap.

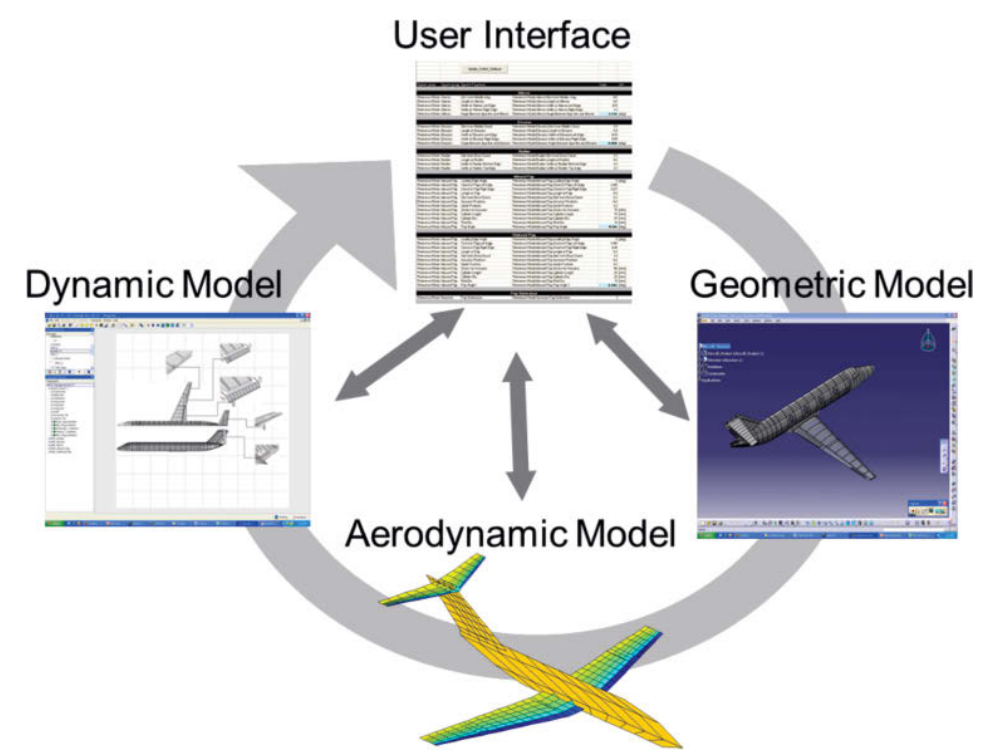

Figure 6.1 Tool Integration using scripts for Optimization

\subsection{Framework with commercial software for opti- mization}

The framework (Figure 6.2) presented in Paper [II], the optimization was implemented using modeFRONTIER. Integration was made between RAPID, Tornado and CAVE. Using the commercial software to integrate different tools makes it easy for the user as he/she need not concern about writing the scripts to connect these tools as presented in Paper [I].

- Aerodynamic model obtains the geometry from RAPID and the simulation is performed to obtain the coefficient of lift and drag. 
- These values are used by CAVE to perform the dynamic simulation to forecast the power consumption and dimensions of the actuator for a specific flight profile.

- The dimensions obtained from the dynamic model are then check in the geometric model for the placement of the actuator and available space.

- Surrogate models were created for the optimization using Anisotropic Kriging method from 300 Uniform Latin Hypercube (ULH) samples. The error between the actual model and surrogate model was $0.05 \%$ for both Geometric model and aerodynamic model and an accuracy of $98.9 \%$ was obtained from the dynamic model.

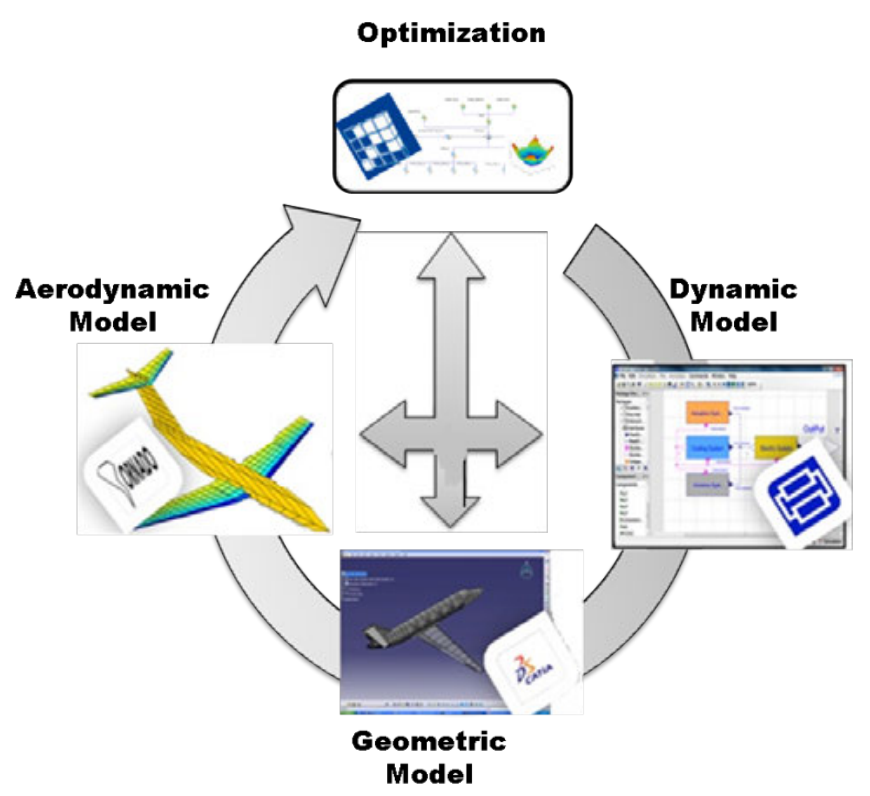

Figure 6.2 Tool Integration using modeFRONTIER for Optimization 


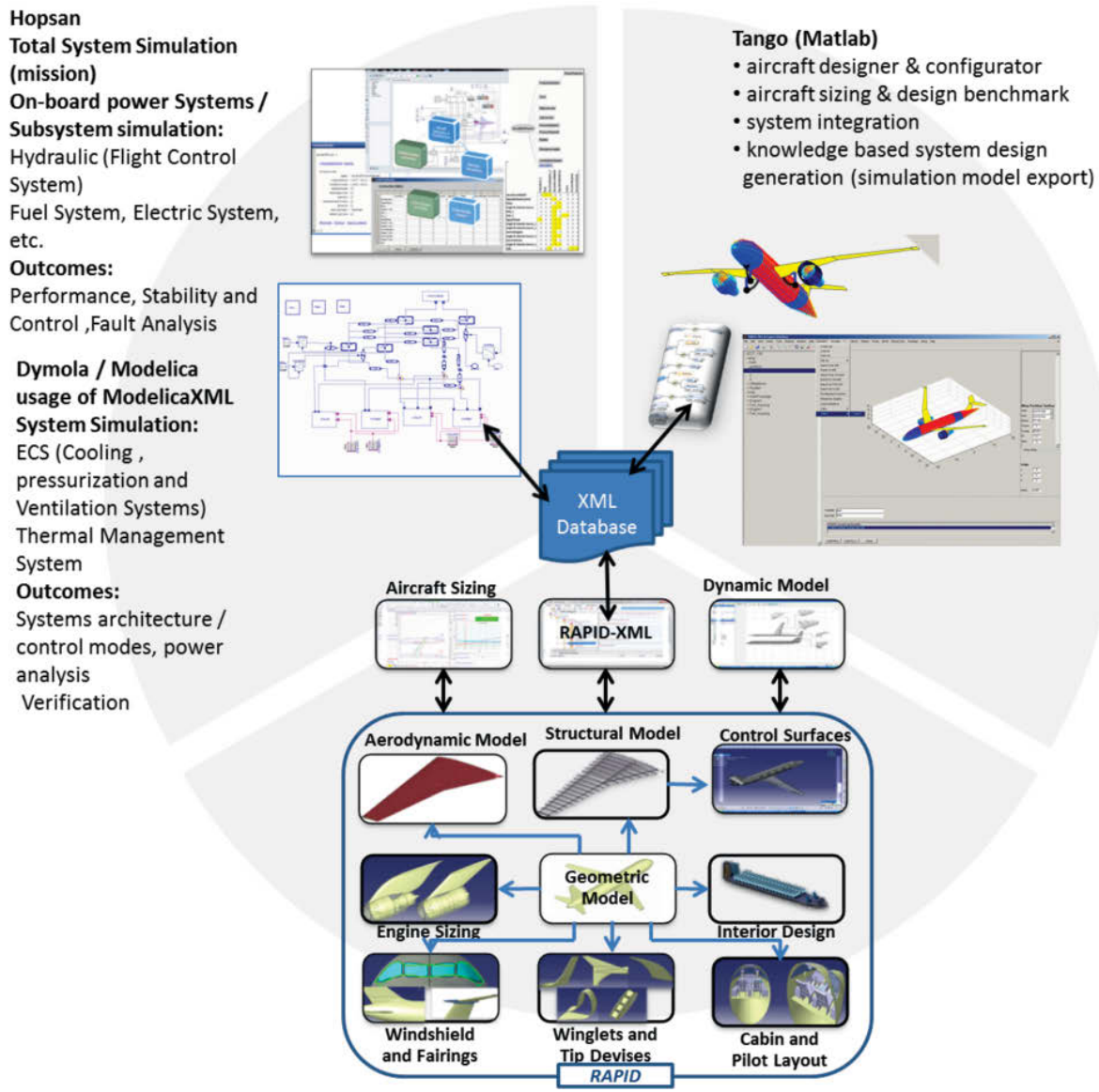

Figure 6.3 Integrated Aircraft Design Network

\subsection{Framework with common database for opti- mization}

The framework (Figure 6.3) presented in Paper [IV], shows different tools RAPID, Tango, Tornado, Hopsan, Dymola and BeX integrated and have common database. The foremost objective was to have two tools Tango and RAPID work in parallel and the user could shift between the programs and the data should be able to exchange between the programs as presented in Paper [V]. Within this framework, traditional handbook methods ([35], [36] and [37]) are employed in the design.

The flow of data between each discipline in a multidisciplinary design 
environment is coupled and saved in XML format [38], [39] and is accessible by all the required tools. The database definition (including several component libraries like functional assemblies) is parametrically defined in such a manner that a data refinement over time alongside the project is possible. In this way, a transition-less process from low or medium fidelity (in e.g. Tango) up to high fidelity (e.g., in RAPID) is realized as shown in Figure 6.3. Simulation models can also be generated out of the (mainly geometry) XML aircraft description . Optimization case is currently in progress 
"High achievement always takes place in the framework of high expectation." - Charles Kettering 


\section{7 \\ Applications of RAPID}

Application examples of RAPID and Tango are presented. RAPID has also been implemented in academia in a couple of courses at Linköping University, the implemented examples are also presented.

\subsection{Data translation RAPID/Tango implementa- tion}

This section shows the application examples of the framework, showing the data build up and data translation between RAPID and Tango and vice versa. Two examples have been tested to investigate the data flow processed in the correct approach. In RAPID, as the user has different options of reference area, this might be difficult to pick the correct method. A number of parameters are accessible for the user in order to obtain various configurations. This might lead to a geometry that is over-defined or has a lot of parameters to play with.

\subsubsection{Civil Aircraft Example}

In this example the double delta reference method is used(Figure 7.1). The cross-sections of the fuselage range from a circle to an ellipse. The data was successfully exchanged in both ways. 


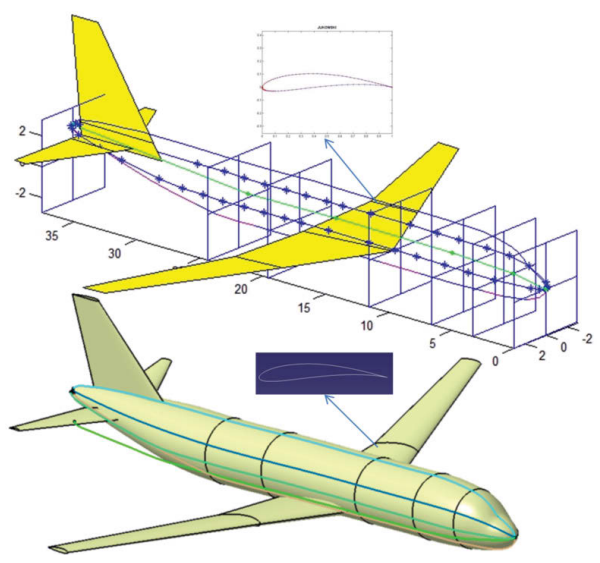

Figure 7.1 Civil Aircraft in Tango (top) and RAPID (bottom).

\subsubsection{Military Aircraft Example}

A much complicated fighter aircraft was selected to test as shown in Figure 7.2. Data exchange showed promising results. It is to notice that the data structure in the background of both examples is similar with modified parameters with added lifting surface "canard" in the fighter example.

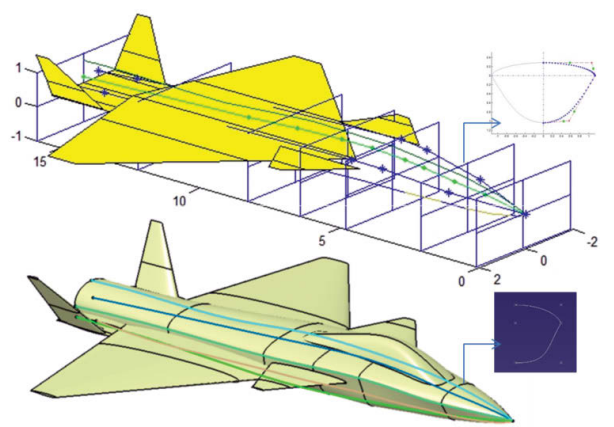

Figure 7.2 Military Aircraft in Tango (top) and RAPID (bottom).

\subsection{Academic Implementation}

To test RAPID and get feedback, the framework has been applied as a "real world test" within undergraduate student courses / aeronautical 
master courses at Linköping University.

\subsubsection{The Jet Family Project}

RAPID was used in the course "Aircraft Conceptual Design" to design a family of turbofan powered aircraft, according to FAR 25 rules. The aircraft family includes three family members with a seat capacity ranging from 75 to 110 (design payload) at 32 inch pitch, but high density versions had to allow for two more rows of seats at a seat pitch of 28 inches. Additionally a two class layout with $15 \%$ business seat capacity for every family member had to be studied with a seat pitch of $34 / 30$ inches (business/economic class). The aircraft family had to be equipped with one and the same wing. The assignment also includes a study on how an optimal designed aircraft should look like (for each family member) and how much the weight and efficiency is deteriorated by keeping the wing unchanged. Interior design for this assignment was very important (as for all civil designs) as it leads to the length of the cabin. It also includes a study on the number of doors and sizes required for each family member. Number of cabin crew required, galleys and toilets for the different aircraft family members has to be figured out. The space required at the emergency exits for evacuation, accessing passenger luggage and cargo on the aircraft needs to be addressed. Also, it is required to consider all kinds of ground handling while on the ground, i.e. the possibility to service the aircraft by means of different vehicles during ground stop.

It is also important to provide the required spacing at the emergency exits for evacuation. Number of toilets, galleys and the number of cabin crew required for the different family members also needs to be figured out. Where to put and access passenger luggage and cargo on the aircraft needs to be addressed. Also to consider all kinds of ground handling while on the ground, i.e. the possibility to service the aircraft by means of different vehicles during ground stop.

- Mdes : 0.82 at $35000 \mathrm{ft}$ for all family members

- Range : $2500 \mathrm{NM}$ at design payload for in-between member of the family

- Reserves : 200nm + 30 min holding

- T-off field length (SL, ISA +20) max : $1900 \mathrm{~m}$ for all members

- Landing field length (SL, ISA +15) max: 1500m for all members 

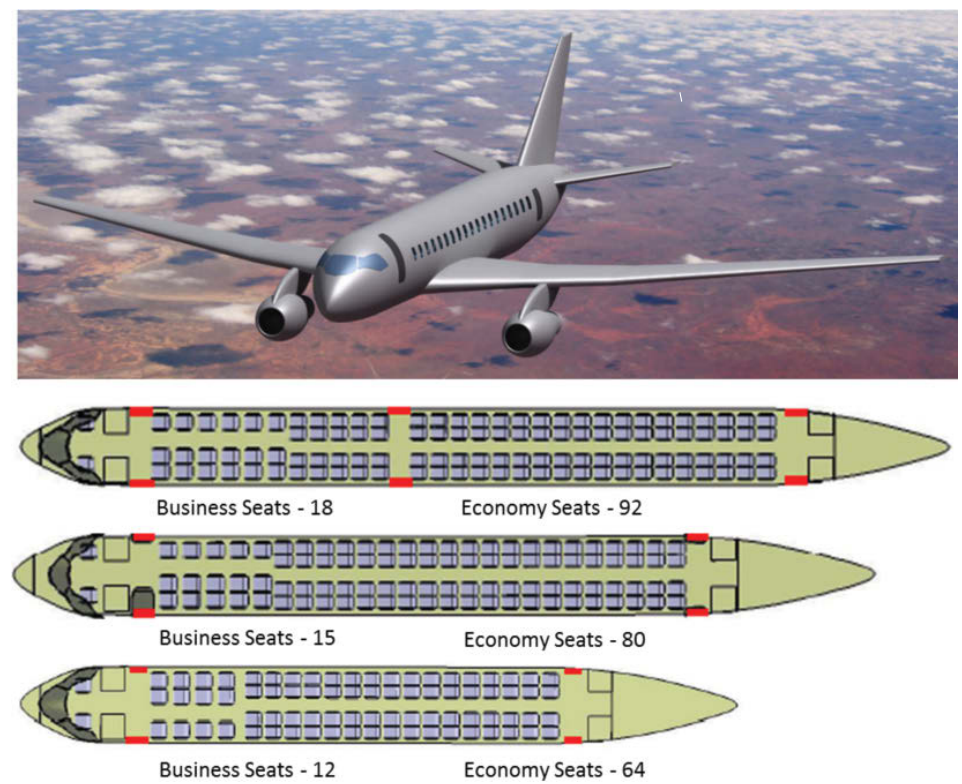

Figure 7.3 One of the student aircraft and interiors with two class seating configurations and an artistic view of the aircraft..

- Individual passenger weight (including luggage) : $110 \mathrm{~kg}$

- Pilots including personal luggage : $104 \mathrm{~kg}$ each

- Attendants (including personal luggage) : $100 \mathrm{~kg}$ each

\subsubsection{The Mid-Jet aircraft Project}

The Mid-Jet project was to build a aerobatic, aesthetic, striking and overwhelming single seat sport jet. To test and demonstrate the flight performance and characteristics a scaled model had to be built. As a first part of the project, a study of existing single seat sport jets was conducted and different concepts were proposed. These ideas were studied from each student team and finally the best concept was chosen for further studies. This concept was then developed in RAPID upto the conceptual design stage for the full scale version of Mid-Jet. From this, a subscaled version intended for the practical design was developed up to the detailed design stage by adding different features to the RAPID model successively. With this model, a demonstrator on a scale of 1:2.8 
was built and successfully flight tested. It is to note that the period between the first design studies until the maiden flight of the demonstrator had only been ca. six months. Particular attention was paid in order to detect the usability of the conceptual/ preliminary design model within the detailed design stage.

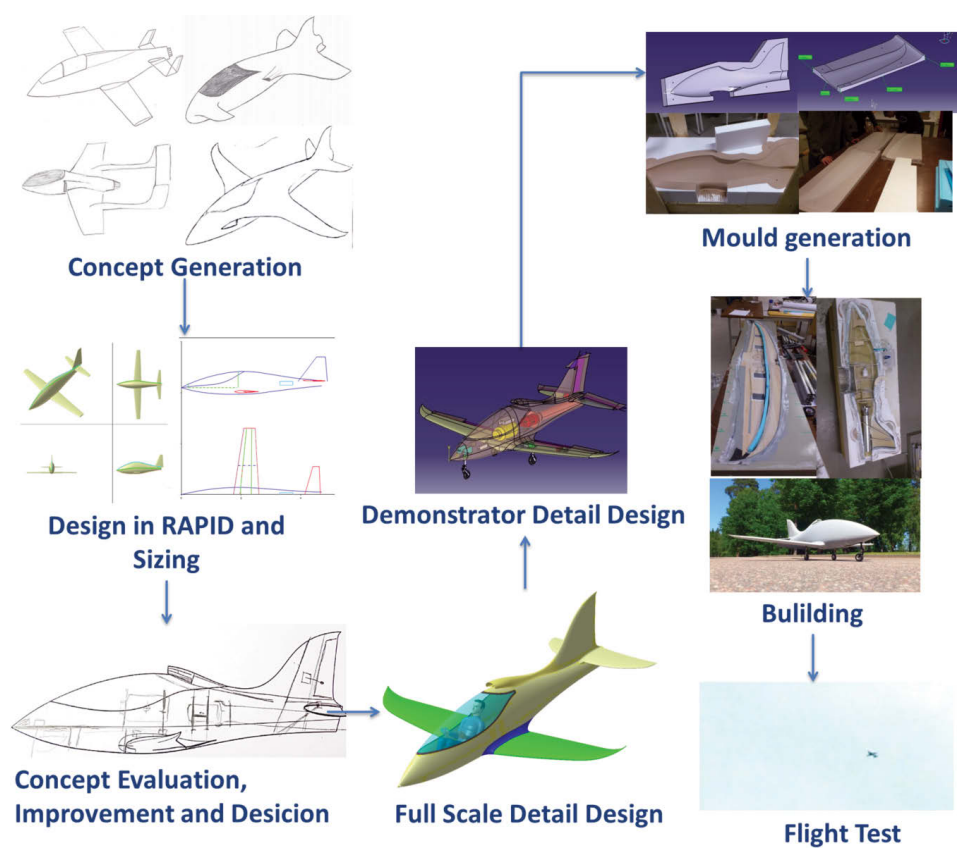

Figure 7.4 Mid-Jet aircraft project process.

\subsubsection{Very Light Jets(VLJs)}

The VLJs project was to design a two-seater and the other a four-seater aircraft. Both the aircrafts were to be designed around DGEN-380 engine. The aircrafts should be flown by normal, average skilled pilots e.g. flying club members. The altitude for the flight was below $20000 \mathrm{ft}$ and the cabins were not pressurized. Main design solutions were presented including seating arrangement, structural layout, entrance door placements and design, engine placement, placing fuel, baggage and basic landing gear design. Weight and general performance of the aircrafts were evaluated along with center of gravity range, stability and trimmability. The artistic view of the aircraft designed in RAPID by the stuents are shown in Figure 7.5. 

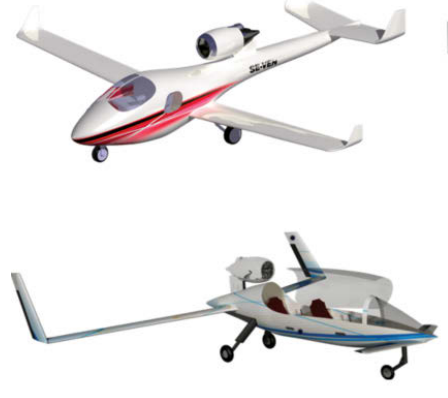
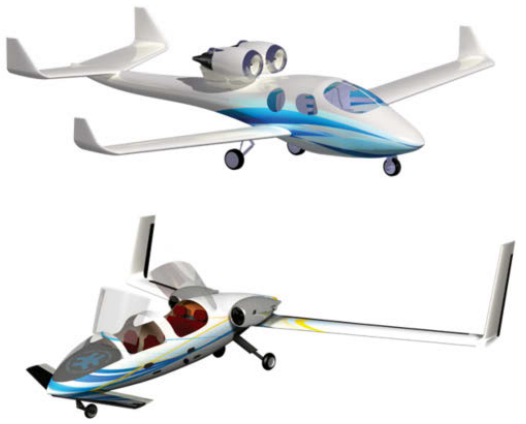

Figure 7.5 Artistic view of students Very Light Jets; Single engine 2-seater (Left), Twin engine 4-seater (Right).

"I have not failed. I've just found 10,000 ways that won't work." Thomas A. Edison 


\section{8 \\ Conclusion}

Aircraft Conceptual design is an iterative process. The designer needs to gain an overview of the aircraft geometry appearances and the design changes that occur during the design process. The geometry plays a major role in the design process and it is needed to be represented in a CAD environment to carry forward to the next level. The geometry created during the processes is desired to change rapidly and also the changes to the geometry need to be realized immediately. KBE methods implemented in early design phases will assist in a wide range of studies that can be conducted with the design and help in the rapid realization of a concept generated during the design process.

The Knowledge based engineering approach is recognized for using in conceptual design. This will facilitate the propagation of the geometry from conceptual to preliminary design. The RAPID tool is developed to aid in the quick geometry creation and eventually studied for a better understanding of aircraft concept. The geometry obtained in RAPID has a very high degree of detail to obtain a wide range of aircraft configurations. A watertight model can be obtained to transfer the geometry to CFD. Effective parameterization is implemented and it is significant for enhanced construction with RAPID. Different fidelity in the geometry can be utilized at the respective stages depending on the need and purpose.

A geometry created in CAD environments encloses a lot of data, e.g. design parameters for creating the concept aircraft, geometrical parameters, etc. Data increase as the design is building up, to save the data and to have a better communication of data with different disciplines an XML database is constructed. This method allows for direct access 
of geometry for other tools, like a geometry optimization outside the CAD environment. Even simulation models could be generated out of the description in XML data. Geometrical data has been successfully implemented between RAPID and Tango.

Different optimization frameworks have been reflected, each framework is different from the other in method and implementation. Different disciplines for the optimization are unified using customized scripts. An enhancement is done by using commercial software for optimization using meta models. The use of meta models for optimization has reduced the time required for optimization and the different experiments could be conducted on the same geometry. A framework is also presented using the XML data setup, supporting in sharing the data with a large group of people for greater collaboration. One tool vs. one database has been discussed and one-database concept is proven to be more effective as each tool is specialized in a specific environment.

"The true method of knowledge is experiment." - William Blake 


\section{9 \\ Outlook}

RAPID as a tool is implemented in academia in different courses, nevertheless, the framework needs to be validated in industry. Further work to effectively distribute the geometry for different disciplines such as aerodynamics, structures etc. needs to be studied and applied. Future work in RAPID includes weight estimation, drag calculations and optimization framework. Improvements in the existing structural model and aerodynamic model are needed to update the mesh automatically so that it can be used in optimization framework. Aircraft systems integration is needed to estimate the volume available for best fit of the components. Some research question need to be answered in future are as follows:

- What methodologies can be applied to break down the structure of a geometric model in CAD environment for making it more robust and speedy update?

- How to make sure that there exists a $\mathrm{C} 2$ continuity between the surfaces after the instantiations in RAPID and how can it be measured?

- In what way can the geometry of aircraft systems be implemented in the early conceptual design?

- Is it advantages to adapt methods like fuzzy logic and neural networks in conceptual design for knowledge-based integrated multidisciplinary optimization?

- In what manner can the database be used effectively without using 
the geometry in knowledge-based integrated multidisciplinary optimization?

"Knowledge is not simply another commodity, On the contrary, Knowledge is never used up. It increases by diffusion and grows by dispersion." - Daniel J. Boorstin 


\section{0}

\section{Review of Papers}

This section presents a short summery of the Papers [I] [II] [III] [IV] appended in this thesis.

\section{Paper I}

\section{Model Based Aircraft Control System Design And Simulation}

An optimization framework is developed for aircraft conceptual design by connecting different disciplines such as CAD, aerodynamics, dynamics with customized scripts. The optimization case is performed to visualize the automation capability of choosing an actuator from the database to enhance the early phases of conceptual design.

\section{Paper II}

\section{Multidisciplinary Optimization of Aircraft Vehicle System for Conceptual Analysis}

An optimization framework is built using modeFRONTIER for RAPID , CAVE and Tornado. Each tool in this framework has a different purpose; RAPID is used for geometry generation, CAVE for dynamic simulation and Tornado for aerodynamic simulation. These tools are connected and an optimization is preformed using meta models. It also shows that the time for an optimization is reduced drastically by using the meta models. 


\section{Paper III}

\section{RAPID - Robust Aircraft Parametric Interactive Design: A Knowledge Based Aircraft Conceptual Design Tool}

RAPID as a tool is presented in this paper. The design methodology followed in building the geometry is explained. Application examples in academia are presented showing the capability of RAPID for conceptual design.

\section{Paper IV}

\section{Integrated Aircraft Design Network}

RAPID, Tango, Tornado, Hopsan and Dymola have been integrated using the one-database concept. XML document is structured and human readable. The methodology used to create the XML document is presented along with application examples that were tested between the two tools.

"If you can dream it, you can do it." - Walt Disney 


\section{Bibliography}

[1] Schminder J. "Feasibility study of different methods for the use in aircraft conceptual design". MA thesis. Linköping: Linköping University, Applied Thermodynamics and Fluid Mechanics, 2012.

[2] Brandt S.A., Stiles R.J., Bertin J.J., and Whitford R. Introduction to Aeronautics: A Design Perspective. AIAA education series. Reston, VA, USA: American Institute of Aeronautics and Astronautics, 1997, p. 391. ISBN: 978-1563473043.

[3] CATIA V5 Release 21. URL: http://www.3ds.com/.

[4] Raymer D. RDS-student: software for aircraft design, sizing, and performance. Vol. 10. Washington DC: AIAA education series, 2006.

[5] Andrew H. "Vehicle Sketch Pad: A Parametric Geometry Modeler for Conceptual Aircraft Design". In: Proc 48th AIAA Aerospace Sciences Meeting. Orlando, Florida: American Institute of Aeronautics and Astronautics, Jan. 2010. DOI: 10.2514/6.2010-657.

[6] Ziemer S. "A conceptual design tool for multi-disciplinary aircraft design". In: Proc Aerospace Conference. IEEE. Big Sky, Montana, USA, Mar. 2011, pp. 1-13. DOI: 10.1109/AERO.2011.5747531.

[7] j2 Universal Framework. URL: http://www.j2aircraft.com/.

[8] ADS. Aircraft Design Software. URL: http://www.pca2000.com.

[9] Piano. Aircraft design and Competitor Analysis. URL: http: // www . piano.aero/.

[10] RAGE. Rapid Aerospace Geometry Engine, Desktop Aeronautics. URL: http://www.desktop. aero/products/rage. 
[11] CEASIOM. Computerized Environment for Aircraft Synthesis and Integrated Optimization Methods software. URL: http:// www . ceasiom.com.

[12] PADLab Software. URL: http: / / www . luftbau . tuberlin.de/ menue/forschung/padlab.

[13] Amadori K. "Geometry Based Design Automation: Applied to Aircraft Modelling and Optimization". PhD thesis. Linköping: Linköping University, Department of Management and Engineering, 2012.

[14] Tarkian M. "Design Automation for Multidisciplinary Optimization. A High Level CAD Template Approach". PhD thesis. Linköping: Linköping University, Department of Management and Engineering, 2012.

[15] Wim J.C. Verhagen, Pablo Bermell-Garcia, Reinier E.C. van Dijk, and Richard Curran. "A critical review of Knowledge-Based Engineering: An identification of research challenges". In: $A d$ vanced Engineering Informatics 26.1 (Jan. 2012), pp. 5-15. ISSN: 14740346. DOI: $10.1016 / \mathrm{j}$.aei.2011.06.004.

[16] Rosenfeld L.W. "Handbook of Solid Modeling". In: ed. by Donald E. LaCourse. New York, USA: McGraw-Hill Inc., 1995. Chap. Solid Modeling and Knowledge-based Engineering, pp. 91911. ISBN: 0-07-035788-9.

[17] Cooper S., Fan I., and Li G. Achieving competitive advantage through knowledge-based engineering: a best practice guide. UK: Department of Trade and Industry (DTI), June 1999.

[18] La Rocca G. and Van Tooren M.J.L. "Enabling distributed multidisciplinary design of complex products: a knowledge based engineering approach". In: Journal of Design Research 5.3 (Aug. 2007), pp. 333-352. ISSN: 1748-3050.

[19] NX. Siemens PLM Software. URL: http://www.plm.automation. siemens.com/en_us/products/nx/for-design/.

[20] Creo. PTC Inc. URL: http : / /www.ptc . com/product/creo/ parametric. 
[21] Wojciech Skarka. "Application of MOKA methodology in generative model creation using CATIA". In: Engineering Applications of Artificial Intelligence 20.5 (2007), pp. 677-690. ISSN: 0952-1976. DOI: http://dx.doi.org/10.1016/j .engappai .2006.11.019.

[22] Rizzi A., Zhang M., Nagel B., Boehnke D., and Saquet P. "Towards a unified framework using CPACS for geometry management in aircraft design". In: 50th AIAA Aerospace Sciences Meeting Including the New Horizons Forum and Aerospace Exposition. Nashville, TN, USA, Jan. 2012, pages. DOI: 10.2514/6. 2012-549.

[23] Böhnke D., Nagel B., and Gollnick V. "An approach to multifidelity in conceptual aircraft design in distributed design environments". In: Proceedings of the 2011 IEEE Aerospace Conference. AERO 11. Washington, DC, USA: IEEE Computer Society, Mar. 2011, pp. 1-10. ISBN: 978-1-4244-7350-2. DOI: 10 . 1109/AERO . 2011.5747542.

[24] Nickol C. Conceptual design shop. Presentation to Conceptual Aircraft Design Working Group (CADWG21). Sept. 2004.

[25] Kulfan B. M. "Universal Parametric Geometry Representation Method". In: Journal of Aircraft 45 (1 Jan. 2008), pp. 142-158. ISSN: 0021-8669. DOI: 10.2514/1.29958.

[26] Melin T. Parametric Airfoil Catalog. 1st ed. Linköping University, 2013, p. 561. ISBN: 978-91-7519-656-5.

[27] Rajendran S. "Design of Parametric Winglets and Wing tip devices : A Conceptual Design Approach". MA thesis. Linköping: Linköping University, 2012.

[28] FAR Rules. URL: http://www.faa.gov/.

[29] Tassel W. "Development of a Complete Parametric CAD Model of a Cockpit Layout for Civil Airplane Under CATIA CAD Software". MA thesis. Linköping University, 2010.

[30] XML and DOM Objects. URL: http://www.w3.org/.

[31] Microsoft Excel. URL: http://www.microsoft.com/.

[32] Microsoft Developer Network. URL: http://msdn .microsoft . com/en-us/library/.

[33] modeFrontier 4.5.2. URL: http://www. esteco.com/modefrontier. 
[34] Amadori K., Tarkian M., Ölvander J., and Krus P. "Flexible and Robust CAD Models for Design Automation". In: Advanced Engineering Informatics 26.2 (Apr. 2012), pp. 180-195. ISSN: 14740346. DOI: $10.1016 / \mathrm{j}$. aei.2012.01.004.

[35] Raymer D. Aircraft design - A Conceptual Approach. 5th ed. Washington DC, USA: AIAA education series, 2012. ISBN: 9781-60086-911-2. DOI: 10.2514/4.869112.

[36] Roskam J. Airplane design. Vol. 2. Kansas: Roskam Aviation and Engineering Corporation, 1985.

[37] Torenbeek E. Synthesis of subsonic airplane design. Delft, Netherlands: Delft University Press, 1995. ISBN: 9024727243.

[38] Lin R. and Abdollah A. "An XML-Based Integrated Database Model for Multidisciplinary Aircraft Design". In: Journal of Aerospace Computing, Information, and Communication 1.3 (Mar. 2004), pp. 154-172. DOI: 10.2514/1.2006.

[39] Ho-Jun Lee, Jae-Woo Lee, and Jeong-Oog Lee. "Development of Web services-based Multidisciplinary Design Optimization framework". In: Advances in Engineering Software 40 (3 Mar. 2009), pp. 176-183. ISSN: 0965-9978. DOI: $10.1016 / \mathrm{j}$. advengsoft . 2008.03.015.

[40] Krus P. "Information Entropy in the Design Process". In: ICoRD'13. Ed. by Amaresh Chakrabarti and Raghu V. Prakash. Lecture Notes in Mechanical Engineering. Springer India, 2013, pp. 101-112. ISBN: 978-81-322-1049-8. DOI: 10 . $1007 / 978-81-$ 322-1050-4_8.

[41] VINNOVA - Swedish national aviation engineering research programme. URL: http://www.vinnova.se/en/Our-activities/ Cooperation-Programmes/National-Aviation-EngineeringResearch-Programme/. 


\section{Papers}

The articles associated with this thesis have been removed for copyright reasons. For more details about these see:

http://urn.kb.se/resolve?urn=urn:nbn:se:liu:diva-106925 